\title{
Taguchi's Orthogonal Arrays Are Classical Designs of Experiments
}

\author{
Raghu N. Kacker, \\ Eric S. Lagergren, and \\ James J. Filliben \\ National Institute of Standards \\ and Technology, \\ Gaithersburg, MD 20899
}

\author{
Taguchi's eatalog of orthogonal arrays is \\ based on the mathematical theory of \\ factorial designs and difference sets \\ developed by R. C. Bose and his associ- \\ ates. These arrays evolved as extensions \\ of factorial designs and latin squares. \\ This paper (1) deseribes the strueture \\ and construetions of Taguchi's orthogo- \\ nal arrays, (2) illustrates their fractional \\ factorial nature, and (3) points out that
}

Taguelii's eatalog ean be expanded to inelude ortlogonal arrays developed sinee 1960 .

Key words: difference sets; fraetional factorial plans; orthogonal arrays; Taguchi's methods.

Accepted: June 5, 1991

\section{Introduction}

Today many engineers are using Taguchi's catalog of orthogonal arrays [1] to plan industrial experiments. But Taguchi provides either no information or insufficient information on the methods that were used to construct these arrays. Moreover, Taguchi displays orthogonal arrays in forms that are different from the way these arrays are usually displayed in the statistical literature. It is, therefore, difficult to discern the links between Taguchi's arrays and their counterparts published elsewhere. Recent advertisements and testimonials of the efficacy of experiments based on Taguchi's orthogonal arrays increase the confusion by giving an impression that these arrays are something other than fractional factorials and classical plans of experiments. This paper describes the structure and constructions of Taguchi's orthogonal arrays, illustrates their fractional factorial nature, and points out that his catalog can be expanded to include orthogonal arrays developed since 1960 .

The next section of this paper provides the background of orthogonal arrays and introduces the concept that an orthogonal array can be displayed in one of many equivalent forms. This concept is subsequently used to exhibit the equivalence of certain well-known fractional factorial plans and Taguchi's orthogonal arrays. Taguchi's catalog contains 20 arrays. However, only 18 of these arrays are orthogonal arrays. These 18 orthogonal arrays are the focus of this paper, and they have been classified into eight groups defined in such a way that the orthogonal arrays in each group can be constructed by a common method. The subsequent eight sections are devoted to these eight specific groups. In these sections, first the constructions of Taguchi's orthogonal arrays are described and then these arrays are related to fractional factorials and other well-known orthogonal arrays. In order to appreciate the factorial nature of Taguchi's orthogonal arrays, it is necessary to understand the constructions of these arrays. The last section of this paper identifies several useful orthogonal arrays that are not in Taguchi's catalog because they were developed after 1960. 


\section{The Background of Orthogonal Arrays}

An orthogonal array (more specifically a fixedelement orthogonal array) of $s$ elements, denoted by $\mathrm{OA}_{N}\left(s^{m}\right)$, is an $N \times m$ matrix whose columns have the property that in every pair of columns each of the possible ordered pairs of elements appears the same number of times. The symbols used for the elements of an orthogonal array are arbitrary. This paper uses the symbols $(0,1,2, \ldots, s-1)$ to denote the $s$ elements. Tables 1 and 2 display $\mathrm{OA}_{4}\left(2^{3}\right)$ and $\mathrm{OA}_{8}\left(2^{7}\right)$ respectively. Note that in every pair of columns of table 1 each of the 4 ordered pairs $(0,0),(0,1),(1,0)$, and $(1,1)$ appears exactly once. Similarly, every pair of columns in table 2 contains each of the four pairs $(0,0),(0,1),(1,0)$, and $(1,1)$ exactly twice. Taguchi refers to $\mathrm{OA}_{N}\left(s^{m}\right)$ by the notation $\mathrm{L}_{N}\left(s^{\prime \prime}\right)$. The letter $\mathrm{L}$ in this notation stands for latin square, and it indicates that orthogonal arrays are generalized latin squares. Taguchi uses the symbols $(1,2, \ldots, s)$ to denote the elements of an orthogonal array. The authors have, however, used the symbols $(0,1, \ldots, s-1)$ in this paper because these symbols are natural in light of the methods of constructing these arrays.

Table 1. Orthogonal array $\mathrm{OA}_{4}\left(2^{3}\right)$

\begin{tabular}{cccc}
\hline & \multicolumn{3}{c}{ Column No. } \\
\cline { 2 - 4 } Row No. & 1 & 2 & 3 \\
\hline 1 & 0 & 0 & 0 \\
2 & 0 & 1 & 1 \\
3 & 1 & 0 & 1 \\
4 & 1 & 1 & 0 \\
\hline
\end{tabular}

Table 2. Orthogonal array $\mathrm{OA}_{\mathrm{B}}\left(2^{7}\right)$

\begin{tabular}{llllllll}
\hline & \multicolumn{7}{c}{ Column No. } \\
\cline { 2 - 8 } Row No. & 1 & 2 & 3 & 4 & 5 & 6 & 7 \\
\hline 1 & 0 & 0 & 0 & 0 & 0 & 0 & 0 \\
2 & 0 & 0 & 0 & 1 & 1 & 1 & 1 \\
3 & 0 & 1 & 1 & 0 & 0 & 1 & 1 \\
4 & 0 & 1 & 1 & 1 & 1 & 0 & 0 \\
5 & 1 & 0 & 1 & 0 & 1 & 0 & 1 \\
6 & 1 & 0 & 1 & 1 & 0 & 1 & 0 \\
7 & 1 & 1 & 0 & 0 & 1 & 1 & 0 \\
8 & 1 & 1 & 0 & 1 & 0 & 0 & 1 \\
\hline
\end{tabular}

Orthogonal arrays can be viewed as plans of multifactor experiments where the columns correspond to the factors, the entries in the columns correspond to the test levels of the factors and the rows correspond to the test runs. More specifically, the $N$ rows of an $\mathrm{OA}_{N}\left(s^{n t}\right)$ can be viewed as a subset of the possible $s^{m}$ test runs of a complete factorial plan in $m$ factors each having $s$ test levels. Thus, an $\mathrm{OA}_{N}\left(s^{m}\right)$ can be viewed as a $N / s^{m}$ fraction of a complete $s^{m}$ factorial plan. For example, the four rows of the $\mathrm{OA}_{4}\left(2^{3}\right)$ that are displayed in Table 1 , can be viewed as a $4 / 2^{3}=1 / 2$ fraction of a complete $2^{3}$ factorial plan.

A sub-matrix formed by deleting some columns of an orthogonal array is also an orthogonal array. Thus, by deleting certain columns of a given orthogonal array, it is possible to generate many different plans of multifactor experiments.

A fractional factorial plan that enables uncorrelated estimation of every factorial effect included in the underlying linear model assuming that all other effects are zero is called an orthogonal plan. Fractional factorial plans based on orthogonal arrays irrespective of the degree of fractionation are necessarily orthogonal plans. This is the primary reason for the popularity of fractional factorials based on orthogonal arrays.

Some of the most popular arrays in Taguchi's catalog are mixed-element (level) orthogonal arrays. A mixed-element orthogonal array, denoted by $\mathrm{OA}_{N}\left(s^{m} \times t^{n}\right)$, is a matrix of $N$ rows and $m+n$ columns in which the first $m$ columns have $s$ elements each, the next $n$ columns have $t$ elements each, and in every pair of columns each of the possible ordered pairs of elements appears a constant number of times. The constant, however, depends on the pair of columns selected. Table 3 displays two orthogonal arrays: $\mathrm{OA}_{18}\left(6^{1} \times 3^{6}\right)^{1}$ and $\mathrm{OA}_{18}\left(2^{1} \times 3^{7}\right)$. Note that every pair of columns in Table 3 contains each of the possible ordered pairs a constant number of times. A mixed-level orthogonal array can be viewed as a fractionated multilevel factorial plan.

It follows from the definition of an orthogonal array that an orthogonal array remains an orthogonal array when its (1) rows are permuted or (2) columns are permuted or (3) the elements within a column are permuted. When orthogonal arrays are viewed as plans of multifactor experiments, the row permutation corresponds to reordering of test runs, the column permutation corresponds to relabeling of factors, and the permutation of elements within a column corresponds to relabeling of factor levels. Most experimenters realize that the labels of factors, 
Table 3. Orthogonal arrays $\mathrm{OA}_{18}\left(6^{1} \times 3^{6}\right)$ and $\mathrm{OA}_{18}\left(2^{1} \times 3^{7}\right)^{\mathrm{a}}$

\begin{tabular}{cccccccccc}
\hline \hline & \multicolumn{10}{c}{ Column No. } \\
\cline { 2 - 9 } Row No. & $1^{\prime}$ & 1 & 2 & 3 & 4 & 5 & 6 & 7 & 8 \\
\hline 1 & 0 & 0 & 0 & 0 & 0 & 0 & 0 & 0 & 0 \\
2 & 0 & 0 & 0 & 1 & 1 & 1 & 1 & 1 & 1 \\
3 & 0 & 0 & 0 & 2 & 2 & 2 & 2 & 2 & 2 \\
4 & 1 & 0 & 1 & 0 & 0 & 1 & 1 & 2 & 2 \\
5 & 1 & 0 & 1 & 1 & 1 & 2 & 2 & 0 & 0 \\
6 & 1 & 0 & 1 & 2 & 2 & 0 & 0 & 1 & 1 \\
7 & 2 & 0 & 2 & 0 & 1 & 0 & 2 & 1 & 2 \\
8 & 2 & 0 & 2 & 1 & 2 & 1 & 0 & 2 & 0 \\
9 & 2 & 0 & 2 & 2 & 0 & 2 & 1 & 0 & 1 \\
10 & 3 & 1 & 0 & 0 & 2 & 2 & 1 & 1 & 0 \\
11 & 3 & 1 & 0 & 1 & 0 & 0 & 2 & 2 & 1 \\
12 & 3 & 1 & 0 & 2 & 1 & 1 & 0 & 0 & 2 \\
13 & 4 & 1 & 1 & 0 & 1 & 2 & 0 & 2 & 1 \\
14 & 4 & 1 & 1 & 1 & 2 & 0 & 1 & 0 & 2 \\
15 & 4 & 1 & 1 & 2 & 0 & 1 & 2 & 1 & 0 \\
16 & 5 & 1 & 2 & 0 & 2 & 1 & 2 & 0 & 1 \\
17 & 5 & 1 & 2 & 1 & 0 & 2 & 0 & 1 & 2 \\
18 & 5 & 1 & 2 & 2 & 1 & 0 & 1 & 2 & 0 \\
\hline
\end{tabular}

a Columns $1^{\prime}, 3,4,5,6,7$, and 8 form $\mathrm{OA}_{18}\left(6^{1} \times 3^{6}\right)$.

Columns $1,2,3,4,5,6,7$, and 8 form $\mathrm{OA}_{18}\left(2^{1} \times 3^{7}\right)$.

the labels of factor levels and the order of test runs are arbitrary. Indeed, the order of test runs is usually randomized. Therefore, two orthogonal arrays are defined to be equivalent if one can be obtained from the other via the following permutations: (1) the rows are permuted, (2) the columns are permuted, and (3) the elements (symbols) within a column are permuted (for example, in a threeelement column, the elements $(0,1$, and 2$)$ can be replaced with any one of their permutations: $(0,2$, and 1$) ;(1,0$, and 2$) ;(1,2$ and 0$) ;(2,0$, and 1$)$; or $(2,1$, and 0$)$ respectively).

Taguchi's format for an orthogonal array has the property that the entries in the left most columns change less frequently than the entries in the right most columns. Therefore, when these arrays are used to plan multifactor experiments, the cost of running the experiment can sometimes be reduced by judiciously associating with the left most columns those factors that are most expensive or most difficult to vary.

Taguchi's catalog contains twenty arrays. However, only eighteen of these twenty arrays are orthogonal arrays. The remaining two arrays, denoted by $\mathrm{L}_{9}{ }_{9}\left(2^{21}\right)$ and $\mathrm{L}_{27}\left(3^{22}\right)$, are not orthogonal arrays and they are not discussed in this paper. The eighteen orthogonal arrays are classified into eight groups based on the common method of construction. The next eight sections are devoted to these eight groups.

\section{Two-Element Orthogonal Arrays of $2^{r}$ Rows for $r=2,3,4,5$, and 6}

The fractional factorial nature of two-element (level) orthogonal arrays follows from the way these arrays are constructed. So this section first describes a simple method of constructing these arrays, then illustrates their fractional factorial nature. A complete two-element orthogonal array with $2^{r}$ rows has $2^{r}-1$ columns and it is constructed column by column in three steps.

Step 1: Write in the $r$ columns specified by column numbers $1,2,4,8, \ldots, 2^{r-1}$ a complete factorial plan in $r$ factors each having two test levels represented by 0 and 1 respectively. In order to match Taguchi's display format, write this plan in such a way that the entries of the left most columns change less frequently than the entries of the right most columns. The entries of these $r$ columns are used to calculate and define the entries of the remaining columns. Therefore, these $r$ columns are referred to as the basic columns and marked as $x_{1}, x_{2}, \ldots, x_{r}$, respectively.

Step 2: These basic columns are used to generate the other columns. The generator of a particular column is a rule of the form $a_{1} x_{1}+a_{2} x_{2}+\ldots+a_{r} x_{r}$ where $x_{1}, x_{2}, \ldots, x_{r}$ are the $r$ basic columns and the coefficients $a_{1}, a_{2}, \ldots a_{r}$ are obtained from the appropriate row of table 4. [For example, in the construction of $\mathrm{OA}_{8}\left(2^{7}\right)$ discussed below, the coefficients $a_{1}, a_{2}, \ldots$, and $a_{3}$ for column 5 are in the fifth row of table 4 and have the values 1,0 , and 1 respectively. This yields $x_{1}+x_{3}$ as the generator for column 5 of $\left.\mathrm{OA}_{8}\left(2^{7}\right)\right]$. List the generators in the order of column numbers.

Step 3: Compute the entries of the other columns by using the generators identified in step 2. The required calculations are performed in modulo 2 arithmetic (that is, $0+0=0, \quad 0+1=1, \quad 1+0=1$ and $1+1=0)$.

This method of construction and analogous methods of constructing three-, four-, and fiveelement orthogonal arrays are based on the mathematical theory of fractional factorials developed by Bose [2]. 
Table 4. Coefficients of the generators of two-element orthogonal arrays of $2^{r}$ rows for $r=2,3, \ldots$

\begin{tabular}{ccccccc}
\hline \hline \multirow{2}{*}{$\begin{array}{c}\text { Column } \\
\text { No. }\end{array}$} & \multicolumn{5}{c}{ Coefficients of $x_{1}, x_{2}, x_{3}, \ldots, x_{r}$} \\
\cline { 2 - 6 } & $a_{1}$ & $a_{2}$ & $a_{3}$ & $\ldots$ & $a_{r-1}$ & $a_{r}$ \\
\hline 1 & 1 & 0 & 0 & First $\left(2^{r-2}-1\right)$ & First $\left(2^{r-1}-1\right)$ \\
2 & 0 & 1 & 0 & entries are 0 & entries are 0 \\
3 & 1 & 1 & 0 & Next $\left(2^{r-2}\right)$ & Last $\left(2^{r-1}\right)$ \\
4 & 0 & 0 & 1 & entries are 1 & entries are 1 \\
5 & 1 & 0 & 1 & Next $\left(2^{r-2}\right)$ & \\
6 & 0 & 1 & 1 & entries are 0 & \\
7 & 1 & 1 & 1 & Last $\left(2^{r-2}\right)$ & \\
$\cdot$ & Repeat Repeat & entries are 1 & \\
$2^{r}-2$ & $(0,1)$ & $(0,0,1,1)$ & & \\
$2^{r}-1$ & 1 & 1 & 1 & 1 & & \\
\hline \multicolumn{7}{c}{} \\
\hline
\end{tabular}

The following example illustrates these steps. Example: Construction of an $\mathrm{OA}_{8}\left(2^{7}\right)$

Here $N=8=2^{3}$, so $r=3$.

Step 1: Write the $r=3$ basic columns.

\begin{tabular}{llllllll} 
Column No. & 1 & 2 & 3 & 4 & 5 & 6 & 7 \\
\hline Row No. & & & & & & \\
1 & 0 & 0 & & 0 & & \\
2 & 0 & 0 & & 1 & & \\
3 & 0 & 1 & & 0 & & \\
4 & 0 & 1 & & 1 & & \\
5 & 1 & 0 & & 0 & & \\
6 & 1 & 0 & 1 & & \\
7 & 1 & 1 & 0 & & \\
8 & 1 & 1 & 1 & & \\
\hline Generator & $x_{1}$ & $x_{2}$ & $x_{3}$ & &
\end{tabular}

Step 2: List the generators (see rows 1 to 7 of table 4).

\begin{tabular}{cl} 
Column No. & Generator \\
\hline 1 & $x_{1}$ \\
2 & $x_{2}$ \\
3 & $x_{1}+x_{2}$ \\
4 & $x_{3}$ \\
5 & $x_{1}+x_{3}$ \\
6 & $x_{2}+x_{3}$ \\
7 & $x_{1}+x_{2}+x_{3}$ \\
\hline
\end{tabular}

Step 3: Complete the array using the generators identified in step 2 .

\begin{tabular}{llllllll} 
Column No. & 1 & 2 & 3 & 4 & 5 & 6 & 7 \\
\hline Row No. & & & & & & & \\
1 & 0 & 0 & 0 & 0 & 0 & 0 & 0 \\
2 & 0 & 0 & 0 & 1 & 1 & 1 & 1 \\
3 & 0 & 1 & 1 & 0 & 0 & 1 & 1 \\
4 & 0 & 1 & 1 & 1 & 1 & 0 & 0 \\
5 & 1 & 0 & 1 & 0 & 1 & 0 & 1 \\
6 & 1 & 0 & 1 & 1 & 0 & 1 & 0 \\
7 & 1 & 1 & 0 & 0 & 1 & 1 & 0 \\
8 & 1 & 1 & 0 & 1 & 0 & 0 & 1 \\
\hline
\end{tabular}

The fractional factorial nature of Taguchi's twoelement orthogonal arrays stems from the fact that the entries of the $r$ columns identified by column numbers $1,2,4,8, \ldots, 2^{r-1}$ form a complete factorial plan, and the remaining columns correspond to the interaction effects. The generators of these columns have a one-to-one correspondence with the main effects and the interaction effects written in Yates' [3] standard order. The $r$ basic columns correspond to the main effects and the remaining columns correspond to the interaction effects.

A two-element (two-level) orthogonal array with $2^{r}$ rows reduces to a fractional factorial plan when more than $r$ factors are associated with the columns of the array and the remaining columns are deleted. In particular, when all $2^{r}-1$ columns are associated with an equal number of factors, a twolevel orthogonal array $\mathrm{OA}_{N}\left(2^{m}\right)$ where $N=2^{r}$ represents a $N / 2^{m}=(1 / 2)^{m-r}$ fraction of a complete $2^{m}$ factorial plan. For example, an $\mathrm{OA}_{8}\left(2^{7}\right)$ represents a $(1 / 2)^{7-3}=(1 / 2)^{4}=1 / 16$ th fraction of a complete $2^{7}$ factorial plan. That is, an $\mathrm{OA}_{8}\left(2^{7}\right)$ represents a $2^{7-4}$ plan in factorial notation.

The test levels of $2^{k-p}$ type fractional factorial plans are usually represented [4] by the symbols - and + . Such plans are often constructed by writing a complete factorial plan in the required number of test runs and appending additional columns obtained by multiplying certain columns of the complete factorial plan. This method and the Bose method of constructing two-level orthogonal arrays described here are similar, but since $(-x-=+,-x+=-$, and $+x+=+)$ while $(0+0=0,0+1=1$, and $1+1=0$ in modulo 2 arithmetic), the two methods yield different fractions of the same type. However, one fraction can be obtained from another of the same type by switching the test levels, and permuting the rows and columns. For example, Taguchi's $\mathrm{OA}_{8}\left(2^{7}\right)$ can be obtained from Box, Hunter, and Hunter's $2^{7-4}$ plan [4] (shown as table 12.5 on page 391 of their book) by switching - and + in columns 4,5 and 6 ; permuting the columns in the order $3,2,6,1,5,4$, and 7 ; and relabeling - as 0 and + as 1 .

\section{Two-Element Orthogonal Array $\mathrm{OA}_{12}\left(2^{11}\right)$}

Table 5 displays Taguchi's $\mathrm{OA}_{12}\left(2^{11}\right)$ in the 0 and 1 notation, and table 6 displays the classic Plackett and Burman [5] plan of 12 runs in the 0 and 1 notation rather than the usual - and + notation. Since table 5 can be obtained 
from table 6 through the following permutations, Taguchi's $\mathrm{OA}_{12}\left(2^{11}\right)$ and the Plackett and Burman plan of 12 runs are equivalent.

(1) In table 6 switch the elements 0 and 1 of columns $1,2,4,5,7$, and 11 (that is, substitute 1 for 0 and 0 for 1 in these columns).

(2) Permute the rows in the following order: $5,2,6,10,4,1,3,7,11,8,12,9$.

(3) Permute the columns in the following order: $1,2,3,4,6,5,9,10,8,7,11$.

Table 5. Orthogonal array $\mathrm{OA}_{12}\left(2^{11}\right)$

\begin{tabular}{cccccccccccc}
\hline \hline & \multicolumn{110}{c}{ Column No. } \\
\cline { 2 - 11 } Row No. & 1 & 2 & 3 & 4 & 5 & 6 & 7 & 8 & 9 & 10 & 11 \\
\hline 1 & 0 & 0 & 0 & 0 & 0 & 0 & 0 & 0 & 0 & 0 & 0 \\
2 & 0 & 0 & 0 & 0 & 0 & 1 & 1 & 1 & 1 & 1 & 1 \\
3 & 0 & 0 & 1 & 1 & 1 & 0 & 0 & 0 & 1 & 1 & 1 \\
4 & 0 & 1 & 0 & 1 & 1 & 0 & 1 & 1 & 0 & 0 & 1 \\
5 & 0 & 1 & 1 & 0 & 1 & 1 & 0 & 1 & 0 & 1 & 0 \\
6 & 0 & 1 & 1 & 1 & 0 & 1 & 1 & 0 & 1 & 0 & 0 \\
7 & 1 & 0 & 1 & 1 & 0 & 0 & 1 & 1 & 0 & 1 & 0 \\
8 & 1 & 0 & 1 & 0 & 1 & 1 & 1 & 0 & 0 & 0 & 1 \\
9 & 1 & 0 & 0 & 1 & 1 & 1 & 0 & 1 & 1 & 0 & 0 \\
10 & 1 & 1 & 1 & 0 & 0 & 0 & 0 & 1 & 1 & 0 & 1 \\
11 & 1 & 1 & 0 & 1 & 0 & 1 & 0 & 0 & 0 & 1 & 1 \\
12 & 1 & 1 & 0 & 0 & 1 & 0 & 1 & 0 & 1 & 1 & 0 \\
\hline
\end{tabular}

Table 6. Plackett and Burman plan of 12 rows

\begin{tabular}{cccccccccccc}
\hline \hline & \multicolumn{110}{c}{ Column No. } \\
\cline { 2 - 10 } Row No. & 1 & 2 & 3 & 4 & 5 & 6 & 7 & 8 & 9 & 10 & 11 \\
\hline 1 & 1 & 0 & 1 & 0 & 0 & 0 & 1 & 1 & 1 & 0 & 1 \\
2 & 1 & 1 & 0 & 1 & 0 & 0 & 0 & 1 & 1 & 1 & 0 \\
3 & 0 & 1 & 1 & 0 & 1 & 0 & 0 & 0 & 1 & 1 & 1 \\
4 & 1 & 0 & 1 & 1 & 0 & 1 & 0 & 0 & 0 & 1 & 1 \\
5 & 1 & 1 & 0 & 1 & 1 & 0 & 1 & 0 & 0 & 0 & 1 \\
6 & 1 & 1 & 1 & 0 & 1 & 1 & 0 & 1 & 0 & 0 & 0 \\
7 & 0 & 1 & 1 & 1 & 0 & 1 & 1 & 0 & 1 & 0 & 0 \\
8 & 0 & 0 & 1 & 1 & 1 & 0 & 1 & 1 & 0 & 1 & 0 \\
9 & 0 & 0 & 0 & 1 & 1 & 1 & 0 & 1 & 1 & 0 & 1 \\
10 & 1 & 0 & 0 & 0 & 1 & 1 & 1 & 0 & 1 & 1 & 0 \\
11 & 0 & 1 & 0 & 0 & 0 & 1 & 1 & 1 & 0 & 1 & 1 \\
12 & 0 & 0 & 0 & 0 & 0 & 0 & 0 & 0 & 0 & 0 & 0 \\
\hline
\end{tabular}

\section{Three-Element Orthogonal Arrays of $3^{r}$ Rows for $r=2,3$, and 4}

A complete three-element orthogonal array with $3^{r}$ rows has $\left(3^{r}-1\right) /(3-1)$ columns and it is constructed in three steps:

Step 1: Write in the $r$ columns specified by column numbers $1,2,5,14, \ldots,\left(3^{r-1}-1\right) /$ $(3-1)+1$ a complete factorial plan in $r$ factors each having three test levels represented by 0,1 , and 2 , respectively. In order to match Taguchi's display format, write this plan in such a way that the entries of the left-most columns change less frequently than do the entries of the right-most columns. Mark these columns as $x_{1}, x_{2}, \ldots, x_{r}$, respectively.

Step 2: As before the generators of the remaining columns are of the form $a_{1} x_{1}+a_{2} x_{2}+\ldots+a_{r} x_{r}$ where $x_{1}, x_{2}, \ldots, x_{r}$ denote the $r$ basic columns and the coefficients $a_{1}, a_{2}, \ldots, a_{r}$ for a particular column are given in the appropriate row of table 7. List the generators in the order of column numbers.

Step 3: Compute the entries of the remaining columns by using the entries of the $r$ basic columns and the appropriate generators. All calculations are done in modulo 3 arithmetic (that is, an integer larger than or equal to three is replaced with its remainder after division by three).

Table 7. Coefficients of the generators of three-element orthogonal arrays of $3^{r}$ rows for $r=2,3, \ldots$

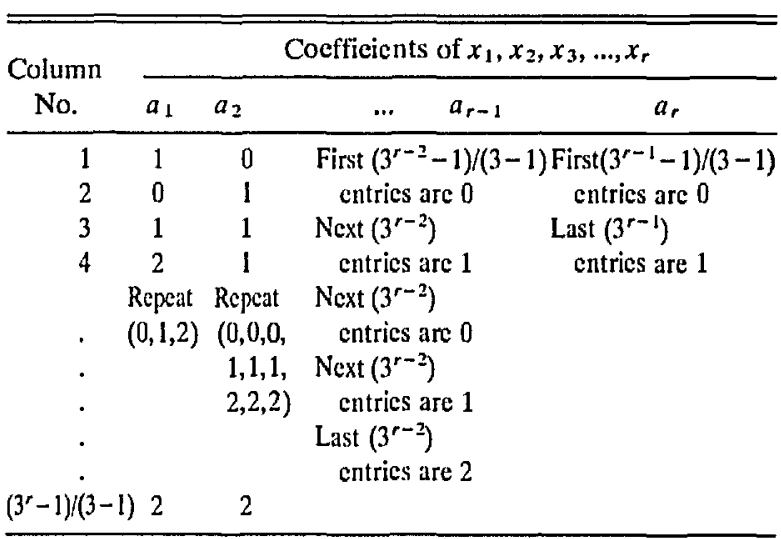


The following example illustrates these steps. Example: Construction of an $\mathrm{OA}_{9}\left(3^{4}\right)$

Here $N=9=3^{2}$, so $r=2$.

Step 1: Write the $r=2$ basic columns

\begin{tabular}{lllll} 
Column No. & 1 & 2 & 3 & 4 \\
\hline Row No. & & & & \\
1 & 0 & 0 & & \\
2 & 0 & 1 & & \\
3 & 0 & 2 & & \\
4 & 1 & 0 & & \\
5 & 1 & 1 & & \\
6 & 1 & 2 & & \\
7 & 2 & 0 & & \\
8 & 2 & 1 & & \\
9 & 2 & 2 & & \\
\hline Generator & $x_{1}$ & $x_{2}$ & &
\end{tabular}

Step 2: List the generators (see rows 1 to 4 of table 7).

\begin{tabular}{ll} 
Column No. & Generator \\
\hline 1 & $x_{1}$ \\
2 & $x_{2}$ \\
3 & $x_{2}+x_{1}$ \\
4 & $x_{2}+2 x_{1}$ \\
\hline
\end{tabular}

Step 3: Complete the array using the generators identified in step 2.

\begin{tabular}{lllll} 
Column No. & 1 & 2 & 3 & 4 \\
\hline Row No. & & & & \\
1 & 0 & 0 & 0 & 0 \\
2 & 0 & 1 & 1 & 1 \\
3 & 0 & 2 & 2 & 2 \\
4 & 1 & 0 & 1 & 2 \\
5 & 1 & 1 & 2 & 0 \\
6 & 1 & 2 & 0 & 1 \\
7 & 2 & 0 & 2 & 1 \\
8 & 2 & 1 & 0 & 2 \\
9 & 2 & 2 & 1 & 0 \\
\hline
\end{tabular}

The fractional factorial nature of Taguchi's three-element orthogonal arrays stems from the fact that the entries of the $r$ basic columns identified by column numbers, $1,2,5,14, \ldots,\left(3^{r-1}-1\right) /(3-1)+1$ form a complete factorial plan and the other columns correspond to the interaction effects. Since each column contains three distinct elements, two degrees of freedom are associated with each column. Since pairwise interaction effects carry $(3-1) \times(3-1)=4$ degrees of freedom, two columns correspond to each pairwise interaction effect. An interaction effect involving $k$ factors carries $(3-1)^{k}=2^{k}$ degrees of freedom. Therefore, $2^{k-1}$ columns correspond to each interaction effect involving $k$ factors for $k=2,3,4, \ldots$.
A three-element (level) orthogonal array with $3^{r}$ rows reduces to a fractional factorial plan when more than $r$ factors are associated with the columns of the array and the remaining columns are deleted. In particular, when all $\left(3^{r}-1\right) /(3-1)$ columns are associated with an equal number of factors, a three-level orthogonal array $\mathrm{OA}_{N}\left(3^{m}\right)$ where $N=3^{r}$ and $m=\left(3^{r}-1\right) /(3-1)$ represents a $N / 3^{m}=(1 / 3)^{m-r}$ fraction of a complete $3^{m}$ factorial plan. For example, an $\mathrm{OA}_{4}\left(3^{4}\right)$ represents a $(1 / 3)^{2}$ fraction of a complete $3^{4}$ factorial plan. That is, an $\mathrm{OA}_{9}\left(3^{4}\right)$ represents a $3^{4-2}$ plan in factorial notation.

\section{Four-Element Orthogonal Arrays of $4^{r}$ Rows for $r=2$ and 3}

The method of constructing four-element orthogonal arrays is similar to the method for threeelement arrays. An important difference, however, is that the calculations required to generate the columns are not performed in modulo 4 arithmetic. Instead, special addition and multiplication tables, displayed here as tables 9 and 10 are used. These addition and multiplication tables are based on the "finite arithmetic of the Galois Field Theory" that underlies this method of construction. According to this theory, the calculations required to generate an orthogonal array of $s$ elements are done in modulo $s$ arithmetic when $s$ is a prime number, as is the case with 2,3 , and 5 . When $s$ is a power of a prime number such as 4 (which is the square of prime number 2), finite arithmetic of a Galois Field of $s$ elements is used. A four-element orthogonal array with $4^{r}$ rows and $\left(4^{r}-1\right) /(4-1)$ columns is constructed in three steps.

Step 1: Write in the $r$ columns specified by column numbers $1,2,6, \ldots,\left(4^{r-1}-1\right) /$ $(4-1)+1$ a complete factorial plan in $r$ factors each having four test levels represented by $0,1,2$, and 3 , respectively. Write this plan in Taguchi's format, and mark these columns as $x_{1}, x_{2}, \ldots, x_{r}$, respectively.

Step 2: As before the generators of the remaining columns are of the form $a_{1} x_{1}+a_{2} x_{2}+\ldots+a_{r} x_{r}$ where $x_{1}, x_{2}, \ldots, x_{r}$ denote the $r$ basic columns and the coeffi-

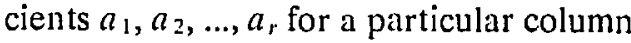
are given in the appropriate row of table 8 . List the generators in the order of column numbers. 
Step 3: Compute the entries of the remaining columns by using the entries of the $r$ basic columns and the appropriate generators. All calculations are done using finite additions and multiplications defined in tables 9 and 10 .

Table 8. Coeffieients of the generators of four-element orthogonal arrays of $4^{r}$ rows for $r=2,3, \ldots$

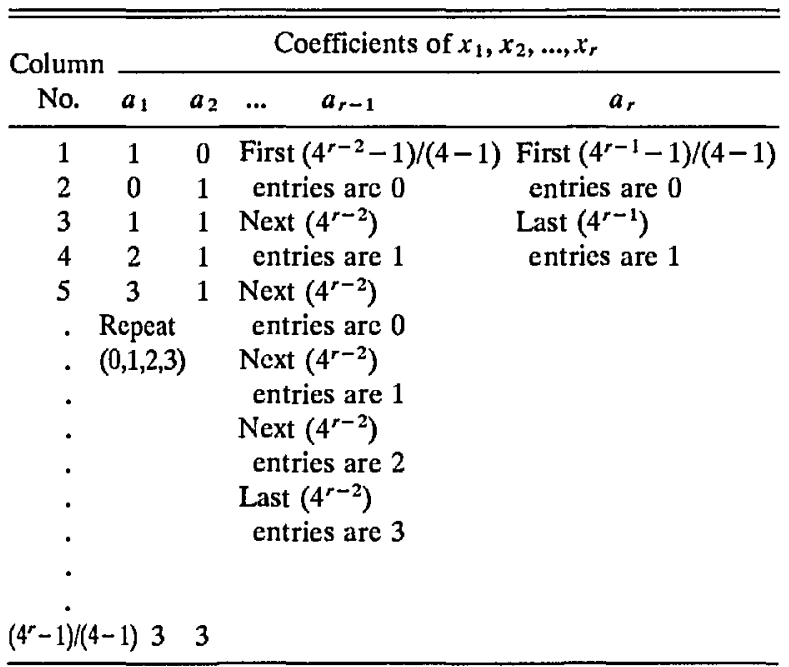

Table 9. Addition table for a Galois field of four elements *

\begin{tabular}{lllll}
\hline \hline+ & 0 & 1 & 2 & 3 \\
\hline 0 & 0 & 1 & 2 & 3 \\
1 & 1 & 0 & 3 & 2 \\
2 & 2 & 3 & 0 & 1 \\
3 & 3 & 2 & 1 & 0 \\
\hline
\end{tabular}

This addition table is also the difference table for a Galois field of four elements.

Table 10. Multiplication table for a Galois field of four elements

\begin{tabular}{ccccc}
\hline \hline$\times$ & 0 & 1 & 2 & 3 \\
\hline 0 & 0 & 0 & 0 & 0 \\
1 & 0 & 1 & 2 & 3 \\
2 & 0 & 2 & 3 & 1 \\
3 & 0 & 3 & 1 & 2 \\
\hline
\end{tabular}

The following example illustrates these steps. Example: Construction of an $\mathrm{OA}_{16}\left(4^{5}\right)$ Here $N=16=4^{2}$, so $r=2$.

Step 1: Write the $r=2$ basic columns

\begin{tabular}{llllll} 
Column No. & 1 & 2 & 3 & 4 & 5 \\
\hline Row No. & & & & & \\
1 & 0 & 0 & & & \\
2 & 0 & 1 & & & \\
3 & 0 & 2 & & & \\
4 & 0 & 3 & & & \\
5 & 1 & 0 & & & \\
6 & 1 & 1 & & & \\
7 & 1 & 2 & & & \\
8 & 1 & 3 & & & \\
9 & 2 & 0 & & & \\
10 & 2 & 1 & & & \\
11 & 2 & 2 & & & \\
12 & 2 & 3 & & & \\
13 & 3 & 0 & & \\
14 & 3 & 1 & & \\
15 & 3 & 2 & & \\
16 & 3 & 3 & & \\
\hline Generator & $x_{1}$ & $x_{2}$ & &
\end{tabular}

Step 2: List the generators (see rows 1 to 5 of table 8).

\begin{tabular}{ll} 
Column No. & Generator \\
\hline 1 & $x_{1}$ \\
2 & $x_{2}$ \\
3 & $x_{2}+x_{1}$ \\
4 & $x_{2}+2 x_{1}$ \\
5 & $x_{2}+3 x_{1}$ \\
\hline
\end{tabular}

Step 3: Complete the array using the generators identified in step 2 and finite additions and multiplications defined in tables 9 and 10.

\begin{tabular}{llllll} 
Column No. & 1 & 2 & 3 & 4 & 5 \\
\hline Row No. & & & & & \\
1 & 0 & 0 & 0 & 0 & 0 \\
2 & 0 & 1 & 1 & 1 & 1 \\
3 & 0 & 2 & 2 & 2 & 2 \\
4 & 0 & 3 & 3 & 3 & 3 \\
5 & 1 & 0 & 1 & 2 & 3 \\
6 & 1 & 1 & 0 & 3 & 2 \\
7 & 1 & 2 & 3 & 0 & 1 \\
8 & 1 & 3 & 2 & 1 & 0 \\
9 & 2 & 0 & 2 & 3 & 1 \\
10 & 2 & 1 & 3 & 2 & 0 \\
11 & 2 & 2 & 0 & 1 & 3 \\
12 & 2 & 3 & 1 & 0 & 2 \\
13 & 3 & 0 & 3 & 1 & 2 \\
14 & 3 & 1 & 2 & 0 & 3 \\
15 & 3 & 2 & 1 & 3 & 0 \\
16 & 3 & 3 & 0 & 2 & 1 \\
\hline
\end{tabular}


The entries of the $r$ basic columns identified by column numbers $1,2,6, \ldots,\left(4^{r-1}-1\right) /(4-1)+1$ form a complete factorial plan and the other columns correspond to the interaction effects. Since each column contains four distinct elements, three degrees of freedom are associated with each column. An interaction effect involving $k$ factors carries $(4-1)^{k}=3^{k}$ degrees of freedom. Therefore, $3^{k-1}$ columns correspond to each interaction effect involving $k$ factors. In particular, three columns correspond to each pairwise interaction effect.

When all $\left(4^{r}-1\right) /(4-1)$ columns are associated with factors, a four-element (four-level) array $\mathrm{OA}_{N}\left(4^{m}\right)$ where $N=4^{r}$ and $m=\left(4^{r}-1\right) /(4-1)$ represents a $N / 4^{m}=(1 / 4)^{m-r}$ fraction of a complete $4^{m}$ factorial plan. For example, $\mathrm{OA}_{16}\left(4^{5}\right)$ represents a $(1 / 4)^{3}$ fraction of a complete $4^{5}$ factorial plan.

\section{Five-Element Orthogonal Array $\mathrm{OA}_{25}\left(5^{6}\right)$}

Taguchi's $\mathrm{OA}_{25}\left(5^{6}\right)$ is constructed through the same general approach that is used to construct 2-, $3-$, and 4-element arrays. The first two columns form a complete factorial plan in two factors each having five test levels represented by $0,1,2,3$, and 4 . The other columns are generated from these two columns using the following generators where $x_{1}$ and $x_{2}$ represent the entries of the first two columns.

\begin{tabular}{lc} 
Column No. & Generator \\
\hline 1 & $x_{1}$ \\
2 & $x_{2}$ \\
3 & $x_{2}+x_{1}$ \\
4 & $x_{2}+2 x_{1}$ \\
5 & $x_{2}+3 x_{1}$ \\
6 & $x_{2}+4 x_{1}$ \\
\hline
\end{tabular}

All calculations are done in modulo 5 arithmetic. When the six columns of an $\mathrm{OA}_{25}\left(5^{6}\right)$ are associated with an equal number of factors, then $\mathrm{OA}_{25}\left(5^{6}\right)$ represents a $(1 / 5)^{4}$ fraction of a complete $5^{6}$ factorial plan.

\section{Mixed-element Orthogonal Arrays $\mathrm{OA}_{18}\left(2^{1} \times 3^{7}\right), \mathrm{OA}_{32}\left(2^{1} \times 4^{9}\right)$ and $\mathrm{OA}_{50}\left(2^{1} \times 5^{11}\right)$}

These orthogonal arrays are constructed by the method of Bose and Bush [6]. This method involves four concepts: difference matrices, Kronecker sums, saturated orthogonal arrays, and column replacement.
1) A difference matrix of $s$ elements $0,1, \ldots,(s-1)$, denoted by $\mathrm{D}_{M}(s)$, is an $M \times M$ matrix whose columns have the property that the differences in finite arithmetic between any two columns is a column in which each of the $s$ elements occurs equally often. Table 11 displays the difference matrix $\mathrm{D}_{3}(3)$. When $s$ is a prime number such as 3 or 5 , the finite arithmetic used in defining the difference matrix is modulo $s$ arithmetic, and when $s$ is a power of a prime number such as 4 (which is the square of prime number 2), the finite arithmetic is the arithmetic of a Galois Field of $s$ elements. Table 9 defines finite addition for $s=4$. The finite difference table for $s=4$ is the same as the finite addition table.

Table 11. Difference matrix $D_{3}(3)$

\begin{tabular}{cccc}
\hline & \multicolumn{3}{c}{ Column No. } \\
\cline { 2 - 4 } Row No. & 1 & 2 & 3 \\
\hline 1 & 0 & 0 & 0 \\
2 & 0 & 1 & 2 \\
3 & 0 & 2 & 1 \\
\hline
\end{tabular}

2) The Kronecker sum of an $M \times M$ difference matrix $\mathrm{D}_{M}(s)$ and a $p \times 1$ vector $b$ of $s$ elements, denoted by $\mathrm{D}_{M}(s) \oplus b$, is a matrix of $M \times p$ rows and $M$ columns obtained by adding in finite arithmetic each element of the vector $b$ to each element of the difference matrix $\mathrm{D}_{M}(s)$. For example, if $b$ is the column vector $(0,1,2)$ and $D_{3}(3)$ is as defined in table 11, then

$\mathrm{D}_{M}(s) \oplus b=\left[\begin{array}{lll}0+0 & 0+0 & 0+0 \\ 0+1 & 0+1 & 0+1 \\ 0+2 & 0+2 & 0+2 \\ & & \\ 0+0 & 1+0 & 2+0 \\ 0+1 & 1+1 & 2+1 \\ 0+2 & 1+2 & 2+2 \\ & & \\ 0+0 & 2+0 & 1+0 \\ 0+1 & 2+1 & 1+1 \\ 0+2 & 2+2 & 1+2\end{array}\right]=\left[\begin{array}{lll}0 & 0 & 0 \\ 1 & 1 & 1 \\ 2 & 2 & 2 \\ 0 & 1 & 2 \\ 1 & 2 & 0 \\ 2 & 0 & 1 \\ 0 & 2 & 1 \\ 1 & 0 & 2 \\ 2 & 1 & 0\end{array}\right]$

3) An orthogonal array $\mathrm{OA}_{N}\left(s^{m} \times t^{n}\right)$ is said to be saturated when $N-1=m(s-1)+n(t-1)$. Since an $s$ element column has $s-1$ degrees of freedom and a $t$ element column has $t-1$ degrees of freedom, $m+n$ columns of $\mathrm{OA}_{N}\left(s^{m} \times t^{n}\right)$ have $m(s-1)+n(t-1)$ degrees of freedom. Since the $N$ rows of $\mathrm{OA}_{N}\left(s^{m} \times t^{n}\right)$ yield $N$ (independent) data values, the total number of effects that can be estimated after allowing for the grand mean of the 
$N$ data values is $N-1$. Therefore when a saturated orthogonal array is used as an experimental plan, the total number of effects that can be estimated is equal to the total degrees of freedom of the columns (factors). When all $m+n$ columns are associated with factors, a saturated orthogonal array can be viewed as a saturated main effect fractional factorial plan.

4) An orthogonal array remains an orthogonal array when one of its columns is replaced with an orthogonal array whose rows have a one-to-one correspondence with the elements of the replaced column. For example, suppose $a$ is a four-element column of an orthogonal array $A$, and suppose $B$ is an orthogonal array whose rows have a one-to-one correspondence with the elements of column $a$ where

$a=\left[\begin{array}{l}0 \\ 1 \\ 2 \\ 3 \\ 3 \\ 2 \\ 1 \\ 0\end{array}\right]$ and $B=\left[\begin{array}{ccc}0 & 0 & 0 \\ 0 & 1 & 1 \\ 1 & 0 & 1 \\ 1 & 1 & 0 \\ 1 & 1 & 0 \\ 1 & 0 & 1 \\ 0 & 1 & 1 \\ 0 & 0 & 0\end{array}\right]$

Then a matrix obtained from the orthogonal array $A$ by replacing the column $a$ with the orthogonal array $B$ is an orthogonal array.

Taguchi's $\mathrm{OA}_{18}\left(2^{1} \times 3^{7}\right), \quad \mathrm{OA}_{32}\left(2^{1} \times 4^{y}\right)$, and $\mathrm{OA}_{50}\left(2^{1} \times 5^{11}\right)$ are constructed by the Bose and Bush method [6] from the difference matrices $\mathrm{D}_{6}(3), \mathrm{D}_{8}(4)$, and $\mathrm{D}_{10}(5)$ displayed in tables 12,13 , and 14 respectively. The following example illustrates the method.

Example: Construction of an $\mathrm{OA}_{18}\left(2^{1} \times 3^{7}\right)$

Step 1: Construct a matrix of $6 \times 3=18$ rows and 6 columns from the Kronecker sum of the difference matrix $\mathrm{D}_{6}(3)$ displayed in table 12 and the column vector $(0,1,2)$. This $18 \times 6$ matrix is displayed in columns $3,4,5,6,7$, and 8 of table 3 , and it is an $\mathrm{OA}_{18}\left(3^{6}\right)$.

Step 2: Append to columns 3,4,5,6,7, and 8 a sixelement column consisting of three 0's, three 1's, three 2's, three 3's, three 4's, and three 5's. Label this column as 1'. Now columns $1^{\prime}, 3,4,5,6,7$, and 8 of table 3 form a saturated orthogonal array $\mathrm{OA}_{18}\left(6^{1} \times 3^{6}\right)$.

Step 3: Construct a matrix of 18 rows and 2 columns by associating the six ordered pairs $(0,0),(0,1),(0,2),(1,0),(1,1)$, and
$(1,2)$ with the 6 elements $0,1,2,3,4$, and 5 of column $1^{\prime}$. This matrix is an orthogonal array and its rows have a one-to-one correspondence with the elements of $1^{\prime}$. Write this orthogonal array in columns 1 and 2 of table 3 . Now columns $1,2,3,4,5,6,7$, and 8 of table 3 form Taguchi's $\mathrm{OA}_{18}\left(2^{1} \times 3^{7}\right)$.

Taguchi's $\mathrm{OA}_{32}\left(2^{1} \times 4^{y}\right)$ and $\mathrm{OA}_{50}\left(2^{1} \times 5^{11}\right)$ are constructed, similarly, from the difference matrices $\mathrm{D}_{8}(4)$ and $\mathrm{D}_{10}(5)$ displayed in Tables 13 and 14, respectively.

Table 12. Taguehi's difference matrix $D_{6}(3)$

\begin{tabular}{ccccccc}
\hline & \multicolumn{1}{c}{ Column No. } \\
\cline { 2 - 7 } Row No. & 1 & 2 & 3 & 4 & 5 & 6 \\
\hline 1 & 0 & 0 & 0 & 0 & 0 & 0 \\
2 & 0 & 0 & 1 & 1 & 2 & 2 \\
3 & 0 & 1 & 0 & 2 & 1 & 2 \\
4 & 0 & 2 & 2 & 1 & 1 & 0 \\
5 & 0 & 1 & 2 & 0 & 2 & 1 \\
6 & 0 & 2 & 1 & 2 & 0 & 1 \\
\hline
\end{tabular}

Table 13. Taguchi's differenee matrix $D_{4}(4)$

\begin{tabular}{ccccccccc}
\hline & \multicolumn{1}{c}{ Column No. } \\
\cline { 2 - 9 } Row No. & 1 & 2 & 3 & 4 & 5 & 6 & 7 & 8 \\
\hline 1 & 0 & 0 & 0 & 0 & 0 & 0 & 0 & 0 \\
2 & 0 & 0 & 1 & 1 & 2 & 2 & 3 & 3 \\
3 & 0 & 1 & 2 & 3 & 0 & 1 & 2 & 3 \\
4 & 0 & 1 & 3 & 2 & 2 & 3 & 1 & 0 \\
5 & 0 & 3 & 0 & 3 & 1 & 2 & 1 & 2 \\
6 & 0 & 3 & 1 & 2 & 3 & 0 & 2 & 1 \\
7 & 0 & 2 & 2 & 0 & 1 & 3 & 3 & 1 \\
8 & 0 & 2 & 3 & 1 & 3 & 1 & 0 & 2 \\
\hline
\end{tabular}

Table 14. Taguchi's differenee matrix $D_{10}(5)$

\begin{tabular}{ccccccccccc}
\hline & \multicolumn{110}{c}{ Column No. } \\
\cline { 2 - 10 } Row No. & 1 & 2 & 3 & 4 & 5 & 6 & 7 & 8 & 9 & 10 \\
\hline 1 & 0 & 0 & 0 & 0 & 0 & 0 & 0 & 0 & 0 & 0 \\
2 & 0 & 1 & 2 & 3 & 4 & 0 & 1 & 2 & 3 & 4 \\
3 & 0 & 2 & 4 & 1 & 3 & 3 & 0 & 2 & 4 & 1 \\
4 & 0 & 3 & 1 & 4 & 2 & 4 & 2 & 0 & 3 & 1 \\
5 & 0 & 4 & 3 & 2 & 1 & 3 & 2 & 1 & 0 & 4 \\
6 & 0 & 0 & 3 & 4 & 3 & 2 & 1 & 4 & 1 & 2 \\
7 & 0 & 1 & 0 & 2 & 2 & 1 & 3 & 4 & 4 & 3 \\
8 & 0 & 2 & 2 & 0 & 1 & 4 & 4 & 3 & 1 & 3 \\
9 & 0 & 3 & 4 & 3 & 0 & 1 & 4 & 1 & 2 & 2 \\
10 & 0 & 4 & 1 & 1 & 4 & 2 & 3 & 3 & 2 & 0 \\
\hline
\end{tabular}


The general method of constructing a mixedelement array of the type $\mathrm{OA}_{N}\left(2^{1} \times s^{m}\right)$ where $m=2 s+1$ and $N=2 s^{2}$ from a difference matrix of the type $\mathrm{D}_{2 s}(s)$ where $s$ is a prime number (such as 3 or 5) or a power of a prime number (such as 4 ) consists of three steps.

Step 1: Construct a matrix of $2 s^{2}$ rows and $2 s$ columns from the Kronecker sum of the difference matrix $\mathrm{D}_{2 s}(s)$ and the column vector $(0,1, \ldots, s-1)$. These $2 s$ columns form $\mathrm{OA}_{N}\left(s^{2 s}\right)$ where $N=2 s^{2}$. Label these columns as $3,4, \ldots$, and $2 s+2$, respectively.

Step 2: Append a $2 s$-element column consisting of $s 0$ 's, $s$ 's, ..., and $s(2 s-1)$ 's. (The total number of entries in the column is $2 s \times s=2 s^{2}$ ). Label this column $1^{\prime}$. Now columns $1^{\prime}, 3,4, \ldots$, and $2 s+2$ form a saturated orthogonal array $\mathrm{OA}_{N}\left[(2 s)^{1} \times s^{2 s}\right]$ where $N=2 s^{2}$.

Step 3: Construct a matrix of $2 s^{2}$ rows and 2 columns by associating the $2 s$ ordered pairs $(0,0), \quad(0,1), \ldots, \quad(0, s-1), \quad(1,0)$, $(1,1), \ldots$. , and $(1, s-1)$ with the $2 s$ elements $0,1, \ldots, s-1, s, s+1, \ldots$, and $2 s-1$ of column 1'. This matrix is an orthogonal array and its rows have a one-to-one correspondence with the elements of column $1 '$. Write this orthogonal array in columns 1 and 2. Now columns $1,2,3, \ldots, 2 s+2$ form $\mathrm{OA}_{N}\left(2^{1} \times s^{m}\right)$ where $N=2 s^{2}$ and $m=2 s+1$.

A difference matrix remains a difference matrix when (1) its rows are permuted or (2) its columns are permuted or (3) an integer is added (in finite arithmetic) to any column of the matrix. Because of finite arithmetic, the addition of an integer to a column results in a permutation of the elements of that column. Thus each of these three operations results in a permutation of the elements of the matrix. The difference matrices $D_{6}(3)$ and $D_{8}(4)$ used by Taguchi are permuted versions of Bose and Bush's $D_{6}(3)$ and $D_{8}(4)$, respectively, and Taguchi's $D_{10}(5)$ is a permuted version of Masuyama's [7] $\mathrm{D}_{10}(5)$. Specifically, Taguchi's $D_{6}(3)$ displayed in table 12 can be obtained from Bose and Bush's $\mathrm{D}_{6}(3)$ displayed in table 15 by permuting the columns of table 15 in the following order: 1,2,3,5,6, and 4. And Taguchi's $\mathrm{D}_{8}(4)$ displayed in table 13 can be obtained from Bose and Bush's $D_{8}(4)$ displayed in table 16 by permuting the columns of table 16 in the following order:
$1,5,2,6,3,7,4$, and 8. Similarly, Taguchi's $D_{10}(5)$ displayed in table 14 can be obtained from Masuyama's $D_{10}(5)$ displayed in table 17 by permuting both the rows and the columns of table 17 in the following order: $1,2,3,4,5,10,6,7,8$, and 9 .

Table 15. Bose and Bush's difference matrix $D_{6}(3)$

\begin{tabular}{ccccccc}
\hline \hline & \multicolumn{1}{c}{ Column No. } \\
\cline { 2 - 7 } Row No. & 1 & 2 & 3 & 4 & 5 & 6 \\
\hline 1 & 0 & 0 & 0 & 0 & 0 & 0 \\
2 & 0 & 0 & 1 & 2 & 1 & 2 \\
3 & 0 & 1 & 0 & 2 & 2 & 1 \\
4 & 0 & 2 & 2 & 0 & 1 & 1 \\
5 & 0 & 1 & 2 & 1 & 0 & 2 \\
6 & 0 & 2 & 1 & 1 & 2 & 0 \\
\hline
\end{tabular}

Table 16. Bose and Bush's difference matrix $D_{x}(4)$

\begin{tabular}{ccccccccc}
\hline \hline & \multicolumn{1}{c}{ Column No. } \\
\cline { 2 - 9 } Row No. & 1 & 2 & 3 & 4 & 5 & 6 & 7 & 8 \\
\hline 1 & 0 & 0 & 0 & 0 & 0 & 0 & 0 & 0 \\
2 & 0 & 1 & 2 & 3 & 0 & 1 & 2 & 3 \\
3 & 0 & 2 & 0 & 2 & 1 & 3 & 1 & 3 \\
4 & 0 & 3 & 2 & 1 & 1 & 2 & 3 & 0 \\
5 & 0 & 0 & 1 & 1 & 3 & 3 & 2 & 2 \\
6 & 0 & 1 & 3 & 2 & 3 & 2 & 0 & 1 \\
7 & 0 & 2 & 1 & 3 & 2 & 0 & 3 & 1 \\
8 & 0 & 3 & 3 & 0 & 2 & 1 & 1 & 2 \\
\hline
\end{tabular}

Table 17. Masuyama's difference matrix $\mathrm{D}_{10}(5)$

\begin{tabular}{ccccccccccc}
\hline & \multicolumn{11}{c}{ Column No. } \\
\cline { 2 - 10 } Row No. & 1 & 2 & 3 & 4 & 5 & 6 & 7 & 8 & 9 & 10 \\
\hline 1 & 0 & 0 & 0 & 0 & 0 & 0 & 0 & 0 & 0 & 0 \\
2 & 0 & 1 & 2 & 3 & 4 & 1 & 2 & 3 & 4 & 0 \\
3 & 0 & 2 & 4 & 1 & 3 & 0 & 2 & 4 & 1 & 3 \\
4 & 0 & 3 & 1 & 4 & 2 & 2 & 0 & 3 & 1 & 4 \\
5 & 0 & 4 & 3 & 2 & 1 & 2 & 1 & 0 & 4 & 3 \\
6 & 0 & 1 & 0 & 2 & 2 & 3 & 4 & 4 & 3 & 1 \\
7 & 0 & 2 & 2 & 0 & 1 & 4 & 3 & 1 & 3 & 4 \\
8 & 0 & 3 & 4 & 3 & 0 & 4 & 1 & 2 & 2 & 1 \\
9 & 0 & 4 & 1 & 1 & 4 & 3 & 3 & 2 & 0 & 2 \\
10 & 0 & 0 & 3 & 4 & 3 & 1 & 4 & 1 & 2 & 2 \\
\hline
\end{tabular}

When all $m+1$ columns are associated with factors, a mixed-element (mixed-level) orthogonal array, $\mathrm{OA}_{N}\left(2^{1} \times s^{m}\right)$, where $N=2 s^{2}$ and $m=2 s+1$ represents a $N /\left(2^{1} \times s^{\prime \prime}\right)=(1 / s)^{m-2}$ fractional factorial plan. For example, $\mathrm{OA}_{18}\left(2^{1} \times 3^{7}\right)$ can be viewed as a $(1 / 3)^{7-2}=(1 / 3)^{5}$ fraction of a complete $2^{1} \times 3^{7}$ factorial plan. 


\section{Mixed-Element Orthogonal Arrays $\mathrm{OA}_{36}\left(2^{11} \times 3^{12}\right)$ and $\mathrm{OA}_{36}\left(2^{3} \times 3^{13}\right)$}

These arrays are constructed by appending certain columns to $\mathrm{OA}_{36}\left(3^{12}\right)$ developed by the Bose and Bush method [6] from the difference matrix $\mathrm{D}_{12}(3)$ displayed in table 19 . The following steps describe the method.

Step 1: Construct a matrix of $12 \times 3=36$ rows and 12 columns from the Kronecker sum of the difference matrix $D_{12}(3)$ displayed in table 19 and the column vector $(0,1,2)$. These twelve columns are displayed in columns $12,13, \ldots$, and 23 of table 18 and they form $\mathrm{OA}_{36}\left(3^{12}\right)$.
Step 2: Append to columns $12,13, \ldots$, and 23 a twelve-element column consisting of three 0 's, three 1 's,..., and three 11's. Label this column as $1^{\prime \prime}$. Now columns $12,13, \ldots, 22,23$, and $1^{\prime \prime}$ form a saturated orthogonal array $\mathrm{OA}_{36}\left(3^{12} \times 12^{1}\right)$.

Step 3: Construct a matrix of $12 \times 3=36$ rows and 11 columns by repeating three times each row of $\mathrm{OA}_{12}\left(2^{11}\right)$ displayed in table 5 . This matrix is an orthogonal array and its rows have a one-to-one correspondence with the twelve elements of column 1 ". Write this orthogonal array in columns $1,2, \ldots, 10$, and 11 . Now columns $1,2, \ldots, 11,12,13, \ldots$, and 23 of table 18 form Taguchi's $\mathrm{OA}_{36}\left(2^{11} \times 3^{12}\right)$.

Table 18. Orthogonal arrays $\mathrm{OA}_{36}\left(2^{11} \times 3^{12}\right), \mathrm{OA}_{36}\left(2^{3} \times 3^{13}\right)$, and $O \mathrm{~A}_{36}\left(3^{12} \times 12^{1}\right)^{\mathrm{a}}$

Column No.

\begin{tabular}{|c|c|c|c|c|c|c|c|c|c|c|c|c|c|c|c|c|c|c|c|c|c|c|c|c|c|c|c|c|}
\hline Row No. & 1 & 2 & 3 & 4 & 5 & 6 & 7 & 8 & 9 & 10 & 11 & 12 & 13 & 14 & 15 & 16 & 17 & 18 & 19 & 20 & 21 & 22 & 23 & $1^{\prime}$ & $2^{\prime}$ & 3 & $4^{\prime}$ & $1^{\prime \prime}$ \\
\hline $\begin{array}{l}1 \\
2 \\
3\end{array}$ & $\begin{array}{l}0 \\
0 \\
0\end{array}$ & $\begin{array}{l}0 \\
0 \\
0\end{array}$ & $\begin{array}{l}0 \\
0 \\
0\end{array}$ & $\begin{array}{l}0 \\
0 \\
0\end{array}$ & $\begin{array}{l}0 \\
0 \\
0\end{array}$ & $\begin{array}{l}0 \\
0 \\
0\end{array}$ & $\begin{array}{l}0 \\
0 \\
0\end{array}$ & $\begin{array}{l}0 \\
0 \\
0\end{array}$ & $\begin{array}{l}0 \\
0 \\
0\end{array}$ & $\begin{array}{l}0 \\
0 \\
0\end{array}$ & $\begin{array}{l}0 \\
0 \\
0\end{array}$ & $\begin{array}{l}0 \\
1 \\
2\end{array}$ & $\begin{array}{l}0 \\
1 \\
2\end{array}$ & $\begin{array}{l}0 \\
1 \\
2\end{array}$ & $\begin{array}{l}0 \\
1 \\
2\end{array}$ & $\begin{array}{l}0 \\
1 \\
2\end{array}$ & $\begin{array}{l}0 \\
1 \\
2\end{array}$ & $\begin{array}{l}0 \\
1 \\
2\end{array}$ & $\begin{array}{l}0 \\
1 \\
2\end{array}$ & $\begin{array}{l}0 \\
1 \\
2\end{array}$ & $\begin{array}{l}0 \\
1 \\
2\end{array}$ & $\begin{array}{l}0 \\
1 \\
2\end{array}$ & $\begin{array}{l}0 \\
1 \\
2\end{array}$ & $\begin{array}{l}0 \\
0 \\
0\end{array}$ & $\begin{array}{l}0 \\
0 \\
0\end{array}$ & $\begin{array}{l}0 \\
0 \\
0\end{array}$ & $\begin{array}{l}0 \\
0 \\
0\end{array}$ & $\begin{array}{l}0 \\
0 \\
0\end{array}$ \\
\hline $\begin{array}{l}4 \\
5 \\
6\end{array}$ & $\begin{array}{l}0 \\
0 \\
0\end{array}$ & $\begin{array}{l}0 \\
0 \\
0\end{array}$ & $\begin{array}{l}0 \\
0 \\
0\end{array}$ & $\begin{array}{l}0 \\
0 \\
0\end{array}$ & $\begin{array}{l}0 \\
0 \\
0\end{array}$ & $\begin{array}{l}1 \\
1 \\
1\end{array}$ & $\begin{array}{l}1 \\
1 \\
1\end{array}$ & $\begin{array}{l}1 \\
1 \\
1\end{array}$ & $\begin{array}{l}1 \\
1 \\
1\end{array}$ & $\begin{array}{l}1 \\
1 \\
1\end{array}$ & $\begin{array}{l}1 \\
1 \\
1\end{array}$ & $\begin{array}{l}0 \\
1 \\
2\end{array}$ & $\begin{array}{l}0 \\
1 \\
2\end{array}$ & $\begin{array}{l}0 \\
1 \\
2\end{array}$ & $\begin{array}{l}0 \\
1 \\
2\end{array}$ & $\begin{array}{l}1 \\
2 \\
0\end{array}$ & $\begin{array}{l}1 \\
2 \\
0\end{array}$ & $\begin{array}{l}1 \\
2 \\
0\end{array}$ & $\begin{array}{l}1 \\
2 \\
0\end{array}$ & $\begin{array}{l}2 \\
0 \\
1\end{array}$ & $\begin{array}{l}2 \\
0 \\
1\end{array}$ & $\begin{array}{l}2 \\
0 \\
1\end{array}$ & $\begin{array}{l}2 \\
0 \\
1\end{array}$ & $\begin{array}{l}0 \\
0 \\
0\end{array}$ & $\begin{array}{l}1 \\
1 \\
1\end{array}$ & $\begin{array}{l}1 \\
1 \\
1\end{array}$ & $\begin{array}{l}0 \\
0 \\
0\end{array}$ & $\begin{array}{l}1 \\
1 \\
1\end{array}$ \\
\hline $\begin{array}{l}7 \\
8 \\
9\end{array}$ & $\begin{array}{l}0 \\
0 \\
0\end{array}$ & $\begin{array}{l}0 \\
0 \\
0\end{array}$ & $\begin{array}{l}1 \\
1 \\
1\end{array}$ & $\begin{array}{l}1 \\
1 \\
1\end{array}$ & $\begin{array}{l}1 \\
1 \\
1\end{array}$ & $\begin{array}{l}0 \\
0 \\
0\end{array}$ & $\begin{array}{l}0 \\
0 \\
0\end{array}$ & $\begin{array}{l}0 \\
0 \\
0\end{array}$ & $\begin{array}{l}1 \\
1 \\
1\end{array}$ & $\begin{array}{l}1 \\
1 \\
1\end{array}$ & $\begin{array}{l}1 \\
1 \\
1\end{array}$ & $\begin{array}{l}0 \\
1 \\
2\end{array}$ & $\begin{array}{l}0 \\
1 \\
2\end{array}$ & $\begin{array}{l}1 \\
2 \\
0\end{array}$ & $\begin{array}{l}2 \\
0 \\
1\end{array}$ & $\begin{array}{l}0 \\
1 \\
2\end{array}$ & $\begin{array}{l}1 \\
2 \\
0\end{array}$ & $\begin{array}{l}2 \\
0 \\
1\end{array}$ & $\begin{array}{l}2 \\
0 \\
1\end{array}$ & $\begin{array}{l}0 \\
1 \\
2\end{array}$ & $\begin{array}{l}1 \\
2 \\
0\end{array}$ & $\begin{array}{l}1 \\
2 \\
0\end{array}$ & $\begin{array}{l}2 \\
0 \\
1\end{array}$ & $\begin{array}{l}1 \\
1 \\
1\end{array}$ & $\begin{array}{l}0 \\
0 \\
0\end{array}$ & $\begin{array}{l}1 \\
1 \\
1\end{array}$ & $\begin{array}{l}0 \\
0 \\
0\end{array}$ & $\begin{array}{l}2 \\
2 \\
2\end{array}$ \\
\hline $\begin{array}{l}10 \\
11 \\
12\end{array}$ & $\begin{array}{l}0 \\
0 \\
0\end{array}$ & $\begin{array}{l}1 \\
1 \\
1\end{array}$ & $\begin{array}{l}0 \\
0 \\
0\end{array}$ & $\begin{array}{l}1 \\
1 \\
1\end{array}$ & $\begin{array}{l}1 \\
1 \\
1\end{array}$ & $\begin{array}{l}0 \\
0 \\
0\end{array}$ & $\begin{array}{l}1 \\
1 \\
1\end{array}$ & $\begin{array}{l}1 \\
1 \\
1\end{array}$ & $\begin{array}{l}0 \\
0 \\
0\end{array}$ & $\begin{array}{l}0 \\
0 \\
0\end{array}$ & $\begin{array}{l}1 \\
1 \\
1\end{array}$ & $\begin{array}{l}0 \\
1 \\
2\end{array}$ & $\begin{array}{l}0 \\
1 \\
2\end{array}$ & $\begin{array}{l}2 \\
0 \\
1\end{array}$ & $\begin{array}{l}1 \\
2 \\
0\end{array}$ & $\begin{array}{l}0 \\
1 \\
2\end{array}$ & $\begin{array}{l}2 \\
0 \\
1\end{array}$ & $\begin{array}{l}1 \\
2 \\
0\end{array}$ & $\begin{array}{l}2 \\
0 \\
1\end{array}$ & $\begin{array}{l}1 \\
2 \\
0\end{array}$ & $\begin{array}{l}0 \\
1 \\
2\end{array}$ & $\begin{array}{l}2 \\
0 \\
1\end{array}$ & $\begin{array}{l}1 \\
2 \\
0\end{array}$ & $\begin{array}{l}1 \\
1 \\
1\end{array}$ & $\begin{array}{l}1 \\
1 \\
1\end{array}$ & $\begin{array}{l}0 \\
0 \\
0\end{array}$ & $\begin{array}{l}0 \\
0 \\
0\end{array}$ & $\begin{array}{l}\mathbf{3} \\
\mathbf{3} \\
\mathbf{3}\end{array}$ \\
\hline $\begin{array}{l}13 \\
14 \\
15\end{array}$ & $\begin{array}{l}0 \\
0 \\
0\end{array}$ & $\begin{array}{l}1 \\
1 \\
1\end{array}$ & $\begin{array}{l}1 \\
1 \\
1\end{array}$ & $\begin{array}{l}0 \\
0 \\
0\end{array}$ & $\begin{array}{l}1 \\
1 \\
1\end{array}$ & $\begin{array}{l}1 \\
1 \\
1\end{array}$ & $\begin{array}{l}0 \\
0 \\
0\end{array}$ & $\begin{array}{l}1 \\
1 \\
1\end{array}$ & $\begin{array}{l}0 \\
0 \\
0\end{array}$ & $\begin{array}{l}1 \\
1 \\
1\end{array}$ & $\begin{array}{l}0 \\
0 \\
0\end{array}$ & $\begin{array}{l}0 \\
1 \\
2\end{array}$ & $\begin{array}{l}1 \\
2 \\
0\end{array}$ & $\begin{array}{l}2 \\
0 \\
1\end{array}$ & $\begin{array}{l}0 \\
1 \\
2\end{array}$ & $\begin{array}{l}2 \\
0 \\
1\end{array}$ & $\begin{array}{l}1 \\
2 \\
0\end{array}$ & $\begin{array}{l}0 \\
1 \\
2\end{array}$ & $\begin{array}{l}2 \\
0 \\
1\end{array}$ & $\begin{array}{l}2 \\
0 \\
1\end{array}$ & $\begin{array}{l}1 \\
2 \\
0\end{array}$ & $\begin{array}{l}0 \\
1 \\
2\end{array}$ & $\begin{array}{l}1 \\
2 \\
0\end{array}$ & $\begin{array}{l}0 \\
0 \\
0\end{array}$ & $\begin{array}{l}0 \\
0 \\
0\end{array}$ & $\begin{array}{l}0 \\
0 \\
0\end{array}$ & $\begin{array}{l}1 \\
1 \\
1\end{array}$ & $\begin{array}{l}4 \\
4 \\
4\end{array}$ \\
\hline $\begin{array}{l}16 \\
17 \\
18\end{array}$ & $\begin{array}{l}0 \\
0 \\
0\end{array}$ & $\begin{array}{l}1 \\
1 \\
1\end{array}$ & $\begin{array}{l}1 \\
1 \\
1\end{array}$ & $\begin{array}{l}1 \\
1 \\
1\end{array}$ & $\begin{array}{l}0 \\
0 \\
0\end{array}$ & $\begin{array}{l}1 \\
1 \\
1\end{array}$ & $\begin{array}{l}1 \\
1 \\
1\end{array}$ & $\begin{array}{l}0 \\
0 \\
0\end{array}$ & $\begin{array}{l}1 \\
1 \\
1\end{array}$ & $\begin{array}{l}0 \\
0 \\
0\end{array}$ & $\begin{array}{l}0 \\
0 \\
0\end{array}$ & $\begin{array}{l}0 \\
1 \\
2\end{array}$ & $\begin{array}{l}1 \\
2 \\
0\end{array}$ & $\begin{array}{l}2 \\
0 \\
1\end{array}$ & $\begin{array}{l}1 \\
2 \\
0\end{array}$ & $\begin{array}{l}0 \\
1 \\
2\end{array}$ & $\begin{array}{l}0 \\
1 \\
2\end{array}$ & $\begin{array}{l}2 \\
0 \\
1\end{array}$ & $\begin{array}{l}1 \\
2 \\
0\end{array}$ & $\begin{array}{l}2 \\
0 \\
1\end{array}$ & $\begin{array}{l}2 \\
0 \\
1\end{array}$ & $\begin{array}{l}1 \\
2 \\
0\end{array}$ & $\begin{array}{l}0 \\
1 \\
2\end{array}$ & 0 & $\begin{array}{l}1 \\
1 \\
1\end{array}$ & $\begin{array}{l}1 \\
1 \\
1\end{array}$ & $\begin{array}{l}1 \\
1 \\
1\end{array}$ & $\begin{array}{l}5 \\
5 \\
5\end{array}$ \\
\hline $\begin{array}{l}19 \\
20 \\
21\end{array}$ & $\begin{array}{l}1 \\
1 \\
1\end{array}$ & $\begin{array}{l}0 \\
0 \\
0\end{array}$ & $\begin{array}{l}1 \\
1 \\
1\end{array}$ & $\begin{array}{l}1 \\
1 \\
1\end{array}$ & $\begin{array}{l}0 \\
0 \\
0\end{array}$ & $\begin{array}{l}0 \\
0 \\
0\end{array}$ & $\begin{array}{l}1 \\
1 \\
1\end{array}$ & $\begin{array}{l}1 \\
1 \\
1\end{array}$ & $\begin{array}{l}0 \\
0 \\
0\end{array}$ & $\begin{array}{l}1 \\
1 \\
1\end{array}$ & $\begin{array}{l}0 \\
0 \\
0\end{array}$ & $\begin{array}{l}0 \\
1 \\
2\end{array}$ & $\begin{array}{l}1 \\
2 \\
0\end{array}$ & $\begin{array}{l}0 \\
1 \\
2\end{array}$ & $\begin{array}{l}2 \\
0 \\
1\end{array}$ & $\begin{array}{l}2 \\
0 \\
1\end{array}$ & $\begin{array}{l}2 \\
0 \\
1\end{array}$ & $\begin{array}{l}0 \\
1 \\
2\end{array}$ & $\begin{array}{l}1 \\
2 \\
0\end{array}$ & $\begin{array}{l}1 \\
2 \\
0\end{array}$ & $\begin{array}{l}0 \\
1 \\
2\end{array}$ & $\begin{array}{l}1 \\
2 \\
0\end{array}$ & $\begin{array}{l}2 \\
0 \\
1\end{array}$ & $\begin{array}{l}1 \\
1 \\
1\end{array}$ & $\begin{array}{l}0 \\
0 \\
0\end{array}$ & $\begin{array}{l}1 \\
1 \\
1\end{array}$ & $\begin{array}{l}1 \\
1 \\
1\end{array}$ & $\begin{array}{l}6 \\
6 \\
6\end{array}$ \\
\hline $\begin{array}{l}22 \\
23 \\
24\end{array}$ & $\begin{array}{l}1 \\
1 \\
1\end{array}$ & $\begin{array}{l}0 \\
0 \\
0\end{array}$ & $\begin{array}{l}1 \\
1 \\
1\end{array}$ & $\begin{array}{l}0 \\
0 \\
0\end{array}$ & $\begin{array}{l}1 \\
1 \\
1\end{array}$ & $\begin{array}{l}1 \\
1 \\
1\end{array}$ & $\begin{array}{l}1 \\
1 \\
1\end{array}$ & $\begin{array}{l}0 \\
0 \\
0\end{array}$ & $\begin{array}{l}0 \\
0 \\
0\end{array}$ & $\begin{array}{l}0 \\
0 \\
0\end{array}$ & $\begin{array}{l}1 \\
1 \\
1\end{array}$ & $\begin{array}{l}0 \\
1 \\
2\end{array}$ & $\begin{array}{l}1 \\
2 \\
0\end{array}$ & $\begin{array}{l}1 \\
2 \\
0\end{array}$ & $\begin{array}{l}2 \\
0 \\
1\end{array}$ & $\begin{array}{l}2 \\
0 \\
1\end{array}$ & $\begin{array}{l}0 \\
1 \\
2\end{array}$ & $\begin{array}{l}1 \\
2 \\
0\end{array}$ & $\begin{array}{l}0 \\
1 \\
2\end{array}$ & $\begin{array}{l}0 \\
1 \\
2\end{array}$ & $\begin{array}{l}2 \\
0 \\
1\end{array}$ & $\begin{array}{l}2 \\
0 \\
1\end{array}$ & $\begin{array}{l}1 \\
2 \\
0\end{array}$ & $\begin{array}{l}1 \\
1 \\
1\end{array}$ & $\begin{array}{l}1 \\
1 \\
1\end{array}$ & $\begin{array}{l}0 \\
0 \\
0\end{array}$ & $\begin{array}{l}1 \\
1 \\
1\end{array}$ & $\begin{array}{l}7 \\
7 \\
7\end{array}$ \\
\hline $\begin{array}{l}25 \\
26 \\
27\end{array}$ & $\begin{array}{l}1 \\
1 \\
1\end{array}$ & $\begin{array}{l}0 \\
0 \\
0\end{array}$ & $\begin{array}{l}0 \\
0 \\
0\end{array}$ & $\begin{array}{l}1 \\
1 \\
1\end{array}$ & $\begin{array}{l}1 \\
1 \\
1\end{array}$ & $\begin{array}{l}1 \\
1 \\
1\end{array}$ & $\begin{array}{l}0 \\
0 \\
0\end{array}$ & $\begin{array}{l}1 \\
1 \\
1\end{array}$ & $\begin{array}{l}1 \\
1 \\
1\end{array}$ & $\begin{array}{l}0 \\
0 \\
0\end{array}$ & $\begin{array}{l}0 \\
0 \\
0\end{array}$ & $\begin{array}{l}0 \\
1 \\
2\end{array}$ & $\begin{array}{l}2 \\
0 \\
1\end{array}$ & $\begin{array}{l}1 \\
2 \\
0\end{array}$ & $\begin{array}{l}0 \\
1 \\
2\end{array}$ & $\begin{array}{l}1 \\
2 \\
0\end{array}$ & $\begin{array}{l}2 \\
0 \\
1\end{array}$ & $\begin{array}{l}2 \\
0 \\
1\end{array}$ & $\begin{array}{l}0 \\
1 \\
2\end{array}$ & $\begin{array}{l}2 \\
0 \\
1\end{array}$ & $\begin{array}{l}0 \\
1 \\
2\end{array}$ & $\begin{array}{l}1 \\
2 \\
0\end{array}$ & $\begin{array}{l}1 \\
2 \\
0\end{array}$ & $\begin{array}{l}0 \\
0 \\
0\end{array}$ & $\begin{array}{l}0 \\
0 \\
0\end{array}$ & $\begin{array}{l}0 \\
0 \\
0\end{array}$ & $\begin{array}{l}2 \\
2 \\
2\end{array}$ & $\begin{array}{l}8 \\
8 \\
8\end{array}$ \\
\hline $\begin{array}{l}28 \\
29 \\
30\end{array}$ & $\begin{array}{l}1 \\
1 \\
1\end{array}$ & $\begin{array}{l}1 \\
1 \\
1\end{array}$ & $\begin{array}{l}1 \\
1 \\
1\end{array}$ & $\begin{array}{l}0 \\
0 \\
0\end{array}$ & $\begin{array}{l}0 \\
0 \\
0\end{array}$ & $\begin{array}{l}0 \\
0 \\
0\end{array}$ & $\begin{array}{l}0 \\
0 \\
0\end{array}$ & $\begin{array}{l}1 \\
1 \\
1\end{array}$ & $\begin{array}{l}1 \\
1 \\
1\end{array}$ & $\begin{array}{l}0 \\
0 \\
0\end{array}$ & $\begin{array}{l}1 \\
1 \\
1\end{array}$ & $\begin{array}{l}0 \\
1 \\
2\end{array}$ & $\begin{array}{l}2 \\
0 \\
1\end{array}$ & $\begin{array}{l}1 \\
2 \\
0\end{array}$ & $\begin{array}{l}1 \\
2 \\
0\end{array}$ & $\begin{array}{l}1 \\
2 \\
0\end{array}$ & $\begin{array}{l}0 \\
1 \\
2\end{array}$ & $\begin{array}{l}0 \\
1 \\
2\end{array}$ & $\begin{array}{l}2 \\
0 \\
1\end{array}$ & $\begin{array}{l}1 \\
2 \\
0\end{array}$ & $\begin{array}{l}2 \\
0 \\
1\end{array}$ & $\begin{array}{l}0 \\
1 \\
2\end{array}$ & $\begin{array}{l}2 \\
0 \\
1\end{array}$ & $\begin{array}{l}0 \\
0 \\
0\end{array}$ & $\begin{array}{l}1 \\
1 \\
1\end{array}$ & $\begin{array}{l}1 \\
1 \\
1\end{array}$ & $\begin{array}{l}2 \\
2 \\
2\end{array}$ & $\begin{array}{l}9 \\
9 \\
9\end{array}$ \\
\hline $\begin{array}{l}31 \\
32 \\
33\end{array}$ & $\begin{array}{l}1 \\
1 \\
1\end{array}$ & $\begin{array}{l}1 \\
1 \\
1\end{array}$ & $\begin{array}{l}0 \\
0 \\
0\end{array}$ & $\begin{array}{l}1 \\
1 \\
1\end{array}$ & $\begin{array}{l}0 \\
0 \\
0\end{array}$ & $\begin{array}{l}1 \\
1 \\
1\end{array}$ & $\begin{array}{l}0 \\
0 \\
0\end{array}$ & $\begin{array}{l}0 \\
0 \\
0\end{array}$ & $\begin{array}{l}0 \\
0 \\
0\end{array}$ & $\begin{array}{l}1 \\
1 \\
1\end{array}$ & $\begin{array}{l}1 \\
1 \\
1\end{array}$ & $\begin{array}{l}0 \\
1 \\
2\end{array}$ & $\begin{array}{l}2 \\
0 \\
1\end{array}$ & $\begin{array}{l}2 \\
0 \\
1\end{array}$ & $\begin{array}{l}2 \\
0 \\
1\end{array}$ & $\begin{array}{l}1 \\
2 \\
0\end{array}$ & $\begin{array}{l}2 \\
0 \\
1\end{array}$ & $\begin{array}{l}1 \\
2 \\
0\end{array}$ & $\begin{array}{l}1 \\
2 \\
0\end{array}$ & $\begin{array}{l}0 \\
1 \\
2\end{array}$ & $\begin{array}{l}1 \\
2 \\
0\end{array}$ & $\begin{array}{l}0 \\
1 \\
2\end{array}$ & $\begin{array}{l}0 \\
1 \\
2\end{array}$ & $\begin{array}{l}1 \\
1 \\
1\end{array}$ & $\begin{array}{l}0 \\
0 \\
0\end{array}$ & $\begin{array}{l}1 \\
1 \\
1\end{array}$ & $\begin{array}{l}2 \\
2 \\
2\end{array}$ & $\begin{array}{l}10 \\
10 \\
10\end{array}$ \\
\hline $\begin{array}{l}34 \\
35 \\
36\end{array}$ & $\begin{array}{l}1 \\
1 \\
1\end{array}$ & $\begin{array}{l}1 \\
1 \\
1\end{array}$ & $\begin{array}{l}0 \\
0 \\
0\end{array}$ & $\begin{array}{l}0 \\
0 \\
0\end{array}$ & $\begin{array}{l}1 \\
1 \\
1\end{array}$ & $\begin{array}{l}0 \\
0 \\
0\end{array}$ & $\begin{array}{l}1 \\
1 \\
1\end{array}$ & $\begin{array}{l}0 \\
0 \\
0\end{array}$ & $\begin{array}{l}1 \\
1 \\
1\end{array}$ & $\begin{array}{l}1 \\
1 \\
1\end{array}$ & $\begin{array}{l}0 \\
0 \\
0\end{array}$ & $\begin{array}{l}0 \\
1 \\
2\end{array}$ & $\begin{array}{l}2 \\
0 \\
1\end{array}$ & $\begin{array}{l}0 \\
1 \\
2\end{array}$ & $\begin{array}{l}1 \\
2 \\
0\end{array}$ & $\begin{array}{l}2 \\
0 \\
1\end{array}$ & $\begin{array}{l}1 \\
2 \\
0\end{array}$ & $\begin{array}{l}2 \\
0 \\
1\end{array}$ & $\begin{array}{l}0 \\
1 \\
2\end{array}$ & $\begin{array}{l}1 \\
2 \\
0\end{array}$ & $\begin{array}{l}1 \\
2 \\
0\end{array}$ & $\begin{array}{l}2 \\
0 \\
1\end{array}$ & $\begin{array}{l}0 \\
1 \\
2\end{array}$ & $\begin{array}{l}1 \\
1 \\
1\end{array}$ & $\begin{array}{l}1 \\
1 \\
1\end{array}$ & $\begin{array}{l}0 \\
0 \\
0\end{array}$ & $\begin{array}{l}2 \\
2 \\
2\end{array}$ & $\begin{array}{l}11 \\
11 \\
11\end{array}$ \\
\hline
\end{tabular}

a Columns $1,2, \ldots, 22$, and 23 form $O_{36}\left(2^{11} \times 3^{12}\right)$.

Columns $1^{\prime \prime}, 12,13, \ldots, 22$, and 23 form $\mathrm{OA}_{36}\left(3^{12} \times 12^{1}\right)$.

Columns $1^{\prime}, 2^{\prime}, 3^{\prime}, 4^{\prime}, 12,13, \ldots, 22$ and 23 form $\mathrm{OA}_{36}\left(2^{3} \times 3^{13}\right)$. 
Step 4: Construct a matrix of 12 rows and 4 columns by repeating $\mathrm{OA}_{4}\left(2^{3}\right)$ displayed in table 1 three times and appending a three-element column consisting of four 0 's, four 1's and four 2's. These four columns form $\mathrm{OA}_{12}\left(2^{3} \times 3^{1}\right)$, and are displayed in table 20 . Now construct a matrix of 36 rows and 4 columns by repeating three times each of the twelve rows of $\mathrm{OA}_{12}\left(2^{3} \times 3^{1}\right)$ displayed in table 20 . This $36 \times 4$ matrix is an orthogonal array of 36 rows and 4 columns and its rows have a one-to-one correspondence with the elements of column $1^{\prime \prime}$. Write this orthogonal array in columns $1^{\prime}, 2^{\prime}, 3^{\prime}$, and $4^{\prime}$ of table 18. Now columns $12,13, \ldots, 23$, $1^{\prime}, 2^{\prime}, 3^{\prime}$, and $4^{\prime}$ of table 18 form Taguchi's $\mathrm{OA}_{36}\left(2^{3} \times 3^{13}\right)$.

The difference matrix $D_{12}(3)$ used by Taguchi is a permuted version of Seiden's [8] $D_{12}$ (3). Specifi-

Table 19. Taguchi's difference matrix $D_{12}(3)$

\begin{tabular}{ccccccccccccc}
\hline & \multicolumn{110}{c}{ Column No. } \\
\cline { 2 - 10 } Now No. & 1 & 2 & 3 & 4 & 5 & 6 & 7 & 8 & 9 & 10 & 11 & 12 \\
\hline 1 & 0 & 0 & 0 & 0 & 0 & 0 & 0 & 0 & 0 & 0 & 0 & 0 \\
2 & 0 & 0 & 0 & 0 & 1 & 1 & 1 & 1 & 2 & 2 & 2 & 2 \\
3 & 0 & 0 & 1 & 2 & 0 & 1 & 2 & 2 & 0 & 1 & 1 & 2 \\
4 & 0 & 0 & 2 & 1 & 0 & 2 & 1 & 2 & 1 & 0 & 2 & 1 \\
5 & 0 & 1 & 2 & 0 & 2 & 1 & 0 & 2 & 2 & 1 & 0 & 1 \\
6 & 0 & 1 & 2 & 1 & 0 & 0 & 2 & 1 & 2 & 2 & 1 & 0 \\
7 & 0 & 1 & 0 & 2 & 2 & 2 & 0 & 1 & 1 & 0 & 1 & 2 \\
8 & 0 & 1 & 1 & 2 & 2 & 0 & 1 & 0 & 0 & 2 & 2 & 1 \\
9 & 0 & 2 & 1 & 0 & 1 & 2 & 2 & 0 & 2 & 0 & 1 & 1 \\
10 & 0 & 2 & 1 & 1 & 1 & 0 & 0 & 2 & 1 & 2 & 0 & 2 \\
11 & 0 & 2 & 2 & 2 & 1 & 2 & 1 & 1 & 0 & 1 & 0 & 0 \\
12 & 0 & 2 & 0 & 1 & 2 & 1 & 2 & 0 & 1 & 1 & 2 & 0 \\
\hline
\end{tabular}

Table 20. Orthogonal array $\mathrm{OA}_{12}\left(2^{3} \times 3^{1}\right)$

\begin{tabular}{ccccc}
\hline \hline & \multicolumn{4}{c}{ Column No. } \\
\cline { 2 - 5 } Row No. & 1 & 2 & 3 & 4 \\
\hline 1 & 0 & 0 & 0 & 0 \\
2 & 0 & 1 & 1 & 0 \\
3 & 1 & 0 & 1 & 0 \\
4 & 1 & 1 & 0 & 0 \\
5 & 0 & 0 & 0 & 1 \\
6 & 0 & 1 & 1 & 1 \\
7 & 1 & 0 & 1 & 1 \\
8 & 1 & 1 & 0 & 1 \\
9 & 0 & 0 & 0 & 2 \\
10 & 0 & 1 & 1 & 2 \\
11 & 1 & 0 & 1 & 2 \\
12 & 1 & 1 & 0 & 2 \\
\hline
\end{tabular}

cally, Taguchi's $D_{12}(3)$ displayed in table 19 can be obtained from Seiden's $D_{12}(3)$ displayed in table 21 through two operations. First add 1 (in modulo 3 arithmetic) to each element of columns 10 and 11, and add 2 to each element of columns 4,5 , and 8 in table 21 , then permute the columns in the following order: $1,2,3,6,12,10,11,5,9,7,8$, and 4 .

When all columns of $\mathrm{OA}_{36}\left(2^{11} \times 3^{12}\right)$ are associated with factors, this array represents a $36 /\left(2^{11} \times 3^{12}\right)$ fraction of a complete $2^{11} \times 3^{12}$ factorial plan; a very highly fractionated orthogonal plan indeed. Similarly $\mathrm{OA}_{36}\left(2^{3} \times 3^{13}\right)$ represents a $36 /\left(2^{3} \times 3^{13}\right)$ fraction of a complete $2^{3} \times 3^{13}$ factorial plan.

Table 21. Sciden's difference matrix $D_{12}(3)$

\begin{tabular}{ccccccccccccc}
\hline & \multicolumn{110}{c}{ Column No. } \\
\cline { 2 - 10 } Row No. & 1 & 2 & 3 & 4 & 5 & 6 & 7 & 8 & 9 & 10 & 11 & 12 \\
\hline 1 & 0 & 0 & 0 & 1 & 1 & 0 & 0 & 1 & 0 & 2 & 2 & 0 \\
2 & 0 & 0 & 0 & 0 & 2 & 0 & 2 & 0 & 2 & 0 & 0 & 1 \\
3 & 0 & 0 & 1 & 0 & 0 & 2 & 1 & 2 & 0 & 0 & 1 & 0 \\
4 & 0 & 0 & 2 & 2 & 0 & 1 & 0 & 0 & 1 & 1 & 0 & 0 \\
5 & 0 & 1 & 2 & 2 & 0 & 0 & 1 & 1 & 2 & 0 & 2 & 2 \\
6 & 0 & 1 & 2 & 1 & 2 & 1 & 2 & 2 & 2 & 2 & 1 & 0 \\
7 & 0 & 1 & 0 & 0 & 2 & 2 & 0 & 2 & 1 & 1 & 2 & 2 \\
8 & 0 & 1 & 1 & 2 & 1 & 2 & 2 & 0 & 0 & 2 & 0 & 2 \\
9 & 0 & 2 & 1 & 2 & 1 & 0 & 0 & 2 & 2 & 1 & 1 & 1 \\
10 & 0 & 2 & 1 & 0 & 0 & 1 & 2 & 1 & 1 & 2 & 2 & 1 \\
11 & 0 & 2 & 2 & 1 & 2 & 2 & 1 & 1 & 0 & 1 & 0 & 1 \\
12 & 0 & 2 & 0 & 1 & 1 & 1 & 1 & 0 & 1 & 0 & 1 & 2 \\
\hline
\end{tabular}

\section{Mixed-Element Orthogonal Array $\mathrm{OA}_{54}\left(2^{1} \times 3^{25}\right)$}

This array is a special case of $\mathrm{OA}_{54}\left(6^{1} \times 3^{24}\right)$ where the six-element column is replaced with two columns one having two elements and the other having three elements. Orthogonal array $\mathrm{OA}_{54}\left(6^{1} \times 3^{24}\right)$ is displayed in table 22 in a special vector form (to save space). In table 22 boldface numbers and letters $0,1,2,3,4,5, a, b$, and $c$ represent the column vectors $(0,0,0),(1,1,1),(2,2,2),(3,3,3)$, $(4,4,4),(5,5,5),(0,1,2),(1,2,0)$, and $(2,0,1)$, respectively. An $\mathrm{OA}_{54}\left(6^{1} \times 3^{24}\right)$ is constructed from $\mathrm{OA}_{18}\left(6^{1} \times 3^{6}\right)$, displayed in table 3 , in three steps. (1) Repeat three times each row of $\mathrm{OA}_{18}\left(6^{1} \times 3^{6}\right)$. (2) Append a column consisting of the vector $(0,1,2)$ repeated eighteen times. (3) Append seventeen additional columns representing the interactions of the columns of $\mathrm{OA}_{18}\left(6^{1} \times 3^{5}\right)$ and the three-element column appended in step 2 . The following paragraphs describe these steps in more detail. 
Table 22. Orthogonal array $\mathrm{OA}_{54}\left(2^{1} \times 3^{25}\right)$, and $\mathrm{OA}_{54}\left(6^{1} \times 3^{24}\right)^{4}$

\begin{tabular}{|c|c|c|c|c|c|c|c|c|c|c|c|c|c|c|c|c|c|c|c|c|c|c|c|c|c|c|c|}
\hline \multirow[b]{2}{*}{ Row No. } & \multicolumn{27}{|c|}{ Column No. } \\
\hline & $1^{\prime}$ & 1 & 2 & 3 & 4 & 5 & 6 & 7 & 8 & 9 & 10 & 11 & 12 & 13 & 14 & 15 & 16 & 17 & 18 & 19 & 20 & 21 & 22 & 23 & 24 & 25 & 26 \\
\hline $1-3$ & 0 & 0 & 0 & 0 & 0 & 0 & 0 & $\mathbf{0}$ & 0 & $a$ & $a$ & $a$ & $a$ & $a$ & $a$ & $a$ & $a$ & $a$ & $a$ & $a$ & $a$ & $a$ & $a$ & $a$ & $a$ & $a$ & $a$ \\
\hline $4-6$ & 0 & 0 & 0 & 1 & 1 & 1 & 1 & 1 & 1 & $a$ & $a$ & $a$ & $a$ & $a$ & $a$ & $\boldsymbol{b}$ & $c$ & $b$ & $c$ & $b$ & $c$ & $b$ & $c$ & $b$ & $c$ & $b$ & $c$ \\
\hline $7-9$ & 0 & 0 & 0 & 2 & 2 & 2 & 2 & 2 & 2 & $a$ & $a$ & $a$ & $a$ & $\boldsymbol{a}$ & $\boldsymbol{a}$ & $c$ & $b$ & $c$ & $b$ & $c$ & $b$ & $c$ & $b$ & $c$ & $b$ & $\boldsymbol{c}$ & $b$ \\
\hline $10-12$ & 1 & 0 & 1 & 0 & $\mathbf{0}$ & 1 & 1 & 2 & 2 & $a$ & $a$ & $b$ & $b$ & $c$ & $c$ & $a$ & $a$ & $a$ & $a$ & $b$ & c & $b$ & $c$ & $c$ & $b$ & $c$ & $b$ \\
\hline $13-15$ & 1 & 0 & 1 & 1 & 1 & 2 & 2 & 0 & 0 & $a$ & $a$ & $b$ & $b$ & $c$ & $c$ & $b$ & $c$ & $b$ & $c$ & $c$ & $b$ & $c$ & $b$ & $a$ & $a$ & $a$ & $a$ \\
\hline $16-18$ & 1 & 0 & 1 & 2 & 2 & 0 & 0 & 1 & 1 & $a$ & $a$ & $\boldsymbol{b}$ & $b$ & $c$ & $c$ & $c$ & $b$ & $c$ & $b$ & $a$ & $a$ & $a$ & $a$ & $b$ & $c$ & $\boldsymbol{b}$ & $c$ \\
\hline $19-21$ & 2 & 0 & 2 & 0 & 1 & 0 & 2 & 1 & 2 & $a$ & $\boldsymbol{b}$ & $a$ & $c$ & $b$ & $c$ & $a$ & $a$ & $b$ & $c$ & $a$ & $\boldsymbol{a}$ & $c$ & $b$ & $b$ & $c$ & $c$ & $b$ \\
\hline $22-24$ & 2 & 0 & 2 & 1 & 2 & 1 & 0 & 2 & 0 & $a$ & $b$ & $a$ & $c$ & $b$ & $c$ & $b$ & $c$ & $c$ & $b$ & $b$ & $c$ & $a$ & $a$ & $c$ & $b$ & $a$ & $a$ \\
\hline $25-27$ & 2 & 0 & 2 & 2 & 0 & 2 & 1 & $\mathbf{0}$ & 1 & $a$ & $b$ & $a$ & $c$ & $b$ & $c$ & $c$ & $b$ & $a$ & $a$ & $c$ & $b$ & $b$ & $c$ & $a$ & $a$ & $b$ & $c$ \\
\hline $28-30$ & 3 & 1 & 0 & 0 & 2 & 2 & 1 & 1 & 0 & $a$ & $c$ & $c$ & $b$ & $b$ & $a$ & $a$ & $a$ & $c$ & $b$ & $c$ & $b$ & $b$ & $c$ & $b$ & $c$ & $a$ & $a$ \\
\hline $31-33$ & 3 & 1 & 0 & 1 & 0 & 0 & 2 & 2 & 1 & $a$ & $c$ & $c$ & $b$ & $\boldsymbol{b}$ & $a$ & $b$ & $c$ & $a$ & $a$ & $a$ & $\boldsymbol{a}$ & $c$ & $b$ & $c$ & $b$ & $b$ & $c$ \\
\hline $34-36$ & 3 & 1 & $\mathbf{0}$ & 2 & 1 & $\mathbf{1}$ & 0 & 0 & 2 & $a$ & $c$ & $c$ & $b$ & $b$ & $a$ & $\boldsymbol{c}$ & $b$ & $b$ & $\boldsymbol{c}$ & $b$ & $c$ & $\boldsymbol{a}$ & $a$ & $a$ & $a$ & $c$ & $b$ \\
\hline $40-42$ & 4 & 1 & 1 & 1 & 2 & 0 & 1 & 0 & 2 & $a$ & $b$ & $c$ & $a$ & $c$ & $b$ & $b$ & $c$ & $c$ & $b$ & $a$ & $a$ & $b$ & $c$ & $a$ & $a$ & $\boldsymbol{c}$ & $b$ \\
\hline $43-45$ & 4 & 1 & 1 & 2 & 0 & 1 & 2 & 1 & 0 & $a$ & $b$ & $c$ & $a$ & $c$ & $b$ & $c$ & $b$ & $a$ & $a$ & $b$ & $c$ & $\boldsymbol{c}$ & $b$ & $b$ & $c$ & $a$ & $a$ \\
\hline $46-48$ & 5 & 1 & 2 & 0 & 2 & 1 & 2 & 0 & 1 & $a$ & $c$ & $b$ & $c$ & $a$ & $b$ & $a$ & $a$ & $c$ & $b$ & $b$ & $c$ & $\boldsymbol{c}$ & $b$ & $a$ & $a$ & $b$ & $c$ \\
\hline $49-51$ & 5 & 1 & 2 & 1 & 0 & 2 & 0 & 1 & 2 & $a$ & $c$ & $b$ & $c$ & $a$ & $b$ & $b$ & $c$ & $a$ & $a$ & $c$ & $\boldsymbol{b}$ & $a$ & $a$ & $b$ & $c$ & $c$ & $b$ \\
\hline $52-54$ & 5 & 1 & 2 & 2 & 1 & 0 & 1 & 2 & 0 & $a$ & $c$ & $b$ & $c$ & $a$ & $b$ & $c$ & $b$ & $\boldsymbol{b}$ & $c$ & $a$ & $a$ & $\boldsymbol{b}$ & $c$ & $c$ & $b$ & $a$ & $a$ \\
\hline
\end{tabular}

${ }^{a}$ Columns $1^{\prime}, 3,4, \ldots, 25$, and 26 form $\mathrm{OA}_{54}\left(6^{1} \times 3^{24}\right)$.

Columns $1,2,3, \ldots, 25$, and 26 form $\mathrm{OA}_{54}\left(2^{1} \times 3^{25}\right)$.

The entries $0,1,2,3,4,5, a, b$, and $c$ represent the column vectors $(0,0,0),(1,1,1),(2,2,2),(3,3,3),(4,4,4),(5,5,5),(0,1,2),(1,2,0)$, and $(2,0,1)$, respectively.

Step 1: Construct a $54 \times 7$ matrix by repeating three times each row of $\mathrm{OA}_{18}\left(6^{1} \times 3^{6}\right)$ displayed in table 3 . This matrix forms the columns $1^{\prime}, 3,4,5,6,7$, and 8 of table 22 .

Step 2: Append to columns 1',3,4,5,6,7, and 8 of table 22, a three-element column consisting of the vector $(0,1,2)$ repeated eighteen times. This is column 9 of table 22 .

Step 3: The seventeen columns identified by column numbers $10,11,12, \ldots, 25$ and 26 of table 22 represent the interactions of column 9 with each of the seven columns $1^{\prime}, 3,4,5,6,7$, and 8 . Since column $1^{\prime}$ has 6 elements ( 5 degrees of freedom) and column 9 has 3 elements ( 2 degrees of freedom), interaction of column $1^{\prime}$ and column 9 has $5 \times 2=10$ degrees of freedom. Thus 5 three-element columns ( 2 degrees of freedom each) are needed to represent the interaction of column $1^{\prime}$ and column 9. These five columns are constructed from columns $2,3,4,5$, and 6 of the difference matrix $D_{6}(3)$ displayed in table 12 as follows. Construct an $18 \times 5$ matrix (not shown in this paper) by delet- ing column 1 of table 12 and repeating three times each row of the remaining five columns. Now construct a matrix of 54 rows and 5 columns by the Kronecker sum of this $18 \times 5$ matrix and the column vector $(0,1,2)$. These five columns are displayed in columns $10,11,12,13$, and 14 of table 22 and they represent the interaction of column $1^{\prime}$ and column 9 .

Since each of the columns $3,4,5,6,7,8$, and 9 has three elements ( 2 degrees of freedom), each pairwise interaction among these columns has 4 degrees of freedom. Thus 2 three-element columns ( 2 degrees of freedom each) are needed to represent each pairwise interaction of column 9 with the columns $3,4,5,6,7$, and 8 . These interaction columns are identified by the method of Bose [2]. This method of construction was used earlier in this paper to construct 2-, 3-, 4-, and 5- element orthogonal arrays. Mark columns 3,4,5,6,7,8, and 9 as $x_{3}, x_{4}, x_{5}, x_{6}, x_{7}, x_{8}$, and $x_{9}$, respectively. These seven columns are used to generate the columns $15,16,17,18,19,20,21,22,23,24,25$, and 26 using the following generators, respectively. 


\begin{tabular}{cl} 
Column No. & Generator \\
\hline 15 & $x_{9}+x_{3}$ \\
16 & $x_{9}+2 x_{3}$ \\
17 & $x_{9}+x_{4}$ \\
18 & $x_{9}+2 x_{4}$ \\
19 & $x_{9}+x_{5}$ \\
20 & $x_{9}+2 x_{5}$ \\
21 & $x_{9}+x_{6}$ \\
22 & $x_{9}+2 x_{6}$ \\
23 & $x_{9}+x_{7}$ \\
24 & $x_{9}+2 x_{7}$ \\
25 & $x_{9}+x_{4}$ \\
26 & $x_{9}+2 x_{5}$ \\
\hline
\end{tabular}

All calculations are done in modulo 3 arithmetic. Note that columns 15 and 16 together represent the four degrees of freedom corresponding to the interaction of column 3 and column 9. Similarly the other columns (in pairs) represent the interactions involving column 9, and columns 4,5,6,7, and 8 , respectively. Now columns $1^{\prime}, 3,4,5, \ldots, 25$, and 26 of table 22 form $\mathrm{OA}_{54}\left(6^{1} \times 3^{24}\right)$.

Taguchi's $\mathrm{OA}_{54}\left(2^{1} \times 3^{25}\right)$ is constructed by replacing column $1^{\prime}$ with two columns formed by associating the 6 ordered pairs $(0,0),(0,1),(0,2)$, $(1,0),(1,1)$, and $(1,2)$ with the elements $0,1,2,3,4$, and 5 of column 1'. These two columns are displayed in columns 1 and 2 of table 22. Now columns $1,2,3,4, \ldots, 25$ and 26 of table 22 form Taguchi's $\mathrm{OA}_{54}\left(2^{1} \times 3^{25}\right)$. When all columns of $\mathrm{OA}_{54}\left(2^{1} \times 3^{25}\right)$ are associated with factors, this array represents a $54 /\left(2^{1} \times 3^{25}\right)$ fraction of a complete $2^{1} \times 3^{25}$ factorial plan.

\section{Concluding Remarks}

As shown in this paper, Taguchi's catalog of orthogonal arrays [1] is primarily based on two papers: Bose [2], and Bose and Bush [6]. The Bose paper laid the mathematical foundation of fractional factorials and orthogonal arrays. The Bose and Bush paper describes a method of constructing mixed-element orthogonal arrays from difference matrices. The difference matrices used by Taguchi to construct $\mathrm{OA}_{18}\left(2^{1} \times 3^{7}\right), \mathrm{OA}_{32}\left(2^{1} \times 4^{y}\right)$, $\mathrm{OA}_{36}\left(2^{11} \times 3^{12}\right), \mathrm{OA}_{36}\left(2^{3} \times 3^{13}\right)$ and $\mathrm{OA}_{50}\left(2^{1} \times 5^{11}\right)$ are permuted versions of the difference matrices developed by Bose and Bush [6], Seiden [8], and Masuyama [7]. The extensions of the Bose, and the Bose and Bush, methods needed to construct $\mathrm{OA}_{36}\left(2^{11} \times 3^{12}\right), \mathrm{OA}_{36}\left(2^{3} \times 3^{13}\right)$, and $\mathrm{OA}_{54}\left(2^{1} \times 3^{25}\right)$ appear to be Taguchi's contributions. The authors have shown that Taguchi's $\mathrm{OA}_{12}\left(2^{11}\right)$ is a permuted version of the Plackett and Burman [5] plan of 12 runs, but there is no reason to believe that Taguchi permuted the Plackett and Burman plan to construct his $\mathrm{OA}_{12}\left(2^{11}\right)$.

Although the original Japanese version of Taguchi's catalog of orthogonal arrays was developed before 1960 , it continues to be very useful. These arrays can be modified to generate many types of multifactor experiments [9] and many other orthogonal arrays can be derived from Taguchi's catalog through established mathematical procedures. Nevertheless, the catalog can now be expanded to include arrays developed after 1960. For example, Taguchi's catalog can be expanded to include $\mathrm{OA}_{24}\left(4^{1} \times 2^{20}\right), \quad \mathrm{OA}_{40}\left(4^{1} \times 2^{36}\right)$ and $\mathrm{OA}_{48}\left(4^{3} \times 2^{38}\right)$ first developed by Dey and Ramakrishna [10] and Chacko, Dey, and Ramakrishna [11], and then re-constructed through a unified procedure by Cheng [12]. It is the authors' intent to develop an expanded and revised version of Taguchi's catalog of orthogonal arrays. A companion paper [13] limited to the fixed-element orthogonal arrays appeared in the Journal of Quality Technology.

About the authors: Raghu N. Kacker, Eric S. Lagergren, and James J. Filliben, are Mathematical Statisticians in the Statistical Engineering Division of the National Institute of Standards and Technology, Computing and Applied Mathematics Laboratory, located at Gaithersburg, Maryland.

\section{References}

[1] G. Taguchi, Orthogonal Arrays and Lincar Graphs, Ameriean Supplicr Institute, Ine., Dearborn, MI (1986).

[2] R. C. Bose, Mathematical Theory of the Symmetrieal Factorial Designs, Sinkhya 8, 107-166 (1947).

[3] F. Yates, The Design and Analysis of Factorial Experiments, Imperial Bureau of Soil Science Tcchnology Communication Number 35, (1937).

[4] G. E. P. Box, W. G. Hunter, and J. S. Hunter, Statisties for Experimenters, John Wiley and Sons, Inc., New York, NY (1978).

[5] R. L. Plackett, and J. P. Burman, The Design of Optimum Multifactorial Experiments, Biometrika 33, 305-325 (1945).

[6] R. C. Bose, and K. A. Bush, Orthogonal Arrays of Strength Two and Three, Annals of Mathematical Statisties 23, 508524 (1952).

[7] M. Masuyama, On Difference Sets for Construeting Orthogonil Arrays of Index Two and of Strength Two, Report on Statistical Applications and Research, JUSE 5, 27-34 (1957).

[8] E. Seiden, On the Problem of Construction of Orthogonal Arrays, Annals of Mathematical Statistics 25, 151-156 (1954). 
[9] G. Taguchi, Systcm of Experimental Design, Vols. 1 and 2, UNIPUB/Kraus International Publications, Whitc Plains, NY (1987).

[10] A. Dey, and G. V. S. Ramakrishna, A Note on Orthogonal Main Effect Plans, Technometrics 19, $511-512$ (1977).

[11] A. Chacko, A. Dey, and G. V. S. Ramakrishna, Orthogonal Main Effect Plans for Asymmetrical Factorials, Tcchnometrics 21, 269-270 (1979).

[12] C. S. Cheng, Some Orthogonal Main-Effcct Plans for Asymmetrical Factorials, Tcchnometrics 31, 475-477 (1989).

[13] R. N. Kacker, E. S. Lagergren, and J. J. Filliben, Taguchi's Fixed-Elcment Arrays are Fractional Factorials, J. Quality Technol. 23, 107-116 (1991). 